\title{
RE-EVALUATION OF NEW ZEALAND SEISMIC HAZARD FOR GEOTECHNICAL ASSESSMENT AND DESIGN
}

\author{
Misko Cubrinovski ${ }^{1}$, Brendon A. Bradley ${ }^{2}$, Frederick Wentz ${ }^{3}$ \\ and Ananth Balachandra ${ }^{4}$
}

(Submitted November 2020; Reviewed March 2021; Accepted May 2021)

\begin{abstract}
This paper scrutinises the seismic hazard of New Zealand (NZ) from a geotechnical engineering perspective. The two codified versions of the seismic hazard in NZS1170.5 (structural loading standard) and NZTA Bridge Manual (NZTA-BM) are shown to yield consistently different peak ground acceleration $(P G A)$ hazards throughout NZ. Results from site-specific PSHA for 24 locations in NZ are used to examine key hazard characteristics, including earthquake magnitude and the effects of site conditions (classes) on the PGA hazard. The comparative evaluations show that for most of the locations considered, NZS1170.5 and NZTA-BM overestimate the PGA hazard. However, NZS1170.5, and NZTA-BM in particular, significantly underestimate the $P G A$ hazard for locations that are at a short source-to-site distance from the Hikurangi Subduction Zone (HSZ), and for which HSZ significantly contributes to their hazard. Using the results from this study, an interim $P G A$ hazard is recommended for geotechnical assessment and design in support of the $\mathrm{NZ}$ guidelines for geotechnical earthquake engineering practice. The recommended interim $P G A$ hazard is applicable to all site classes without any modification or use of site amplification factors.
\end{abstract}

\section{INTRODUCTION}

Probabilistic Seismic Hazard Analysis (PSHA) is the cornerstone methodology that provides science-based hazard information for seismic assessment and design of land, buildings and infrastructure. PSHA is complex and incorporates many important assumptions and considerations, but generally it involves three principal steps: (i) characterisation of earthquake sources; (ii) estimation of ground shaking intensity for a given source realisation (rupture); and (iii) aggregation of the effects of steps 1 and 2 over all relevant earthquake sources and combinations of factors (e.g., [1]). One of the principal outputs from PSHA is the seismic hazard curve which provides an estimate for the likelihood of a particular ground shaking intensity being exceeded at the site of interest, in any given year, or during the design life of the structure. In principle, various intensity measures could be used to quantify the ground shaking intensity in PSHA.

\section{Ground Motion Parameters for Geotechnical Design}

The peak ground acceleration $(P G A)$ and earthquake magnitude $(M)$ are commonly used as proxies for the amplitude and duration of the ground motion in conventional geotechnical assessment based on simplified equivalent-static procedures. For example, in the seismic assessment of slopes, embankments and dams, $P G A$ is used to estimate the seismic coefficient and crest accelerations (i.e., inertial response of the earth body), and $M$ is used to quantify the effects of significant duration (i.e., the number of significant-amplitude cycles) in the estimation of ground displacements (e.g., [2,3]). Similarly, $P G A$ is used to estimate earth pressure coefficients, and the combined effects of amplitude and duration of ground motion are considered when estimating permanent displacements in the design of earth-retaining structures. Newmark's sliding block analysis method [4] is often conceptually behind such displacement calculations. Finally, in a simplified evaluation of soil liquefaction, $P G A$ and $M$ are explicitly required to quantify the seismic demand in the analysis of triggering and consequences of liquefaction (e.g., [5]). For the above reasons, $P G A$ and $M$ are commonly required parameters to be estimated from PSHA.

It is important to emphasise that frequency characteristics of the seismic demand and response are additionally considered in the simplified equivalent-static procedures. In geotechnical design of structures (i.e., buildings, bridges, etc.), spectral accelerations (and other parameters) are directly used to account for effects of structural response in the assessment. Thus, the emphasis on $P G A$ and $M$ in geotechnical considerations should be seen as complementary in nature, and as an additional requirement, rather than an alternative form of hazard presentation to that typically used in structural loading standards.

\section{Guidance for Earthquake Geotechnical Engineering Practice in NZ}

Over the past decade, a series of guideline documents (modules) have been developed for the earthquake geotechnical practice in NZ. The first document in the series, which focused on the evaluation of soil liquefaction, was published in July 2010 [6], just two months before the initiation of the Canterbury Earthquake Sequence (CES). It was a well-received and timely document in the profession, as the CES caused widespread, and very damaging, liquefaction in Christchurch $[7,8]$. Following the CES, a series of six modules were produced and published in 2016, as Revision 0 [9], with the following focus:

Module 1: Overview and ground-motion parameters

Module 2: Site investigations

Module 3: Assessment of liquefaction hazards

Module 4: Earthquake-resistant foundation design

Module 5: Ground improvement

Module 6: Retaining walls

\footnotetext{
1 Professor, University of Canterbury, Christchurch, misko.cubrinovski@canterbury.ac.nz (Fellow)

2 Professor, University of Canterbury, Christchurch (Member)

3 Director, Wentz-Pacific Limited, Napier (Member)

4 Geotechnical Engineer, Tonkin+Taylor, Auckland
} 
Currently, the work on Revision 1 of the modules is underway, and the hazard study presented in this paper and in Bradley et al. [1] is in support of the revision of Module 1 of the geotechnical guidelines.

In the initial version of the guidelines [6], the seismic hazard presented in NZS1170.5 (structural loading standard) [10] was adopted for use. It was recognised at the time that the magnitude-weighted seismic hazard factor $(Z)$ presented in NZS1170.5 was not appropriate for use in earthquake geotechnical engineering practice. However, the NZS1170.5 hazard was adopted as it was the only available codified interpretation of the NZ seismic hazard at the time.

To address the magnitude-weighting deficiency in the NZS1170.5 hazard, the NZTA Bridge Manual (NZTA-BM) [11-13] presented unweighted $P G A$ coefficients $\left(C_{0,1000)}\right.$ and corresponding 'effective' (earthquake) magnitudes $\left(M_{e f f}\right)$. Hence, in the Revision 0 of the MBIE-NZGS geotechnical guideline series published in 2016 [9], it was recommended to discontinue the use of the magnitude-weighted seismic hazard presented in NZS1170.5, and instead use the NZTA-BM unweighted $P G A \mathrm{~s}$ and the corresponding $M_{\text {eff. }}$ NZTA-BM was adopted as it was considered more appropriate for geotechnical assessment, and it was assumed that both the NZS1170.5 and NZTA-BM hazards were consistent, compatible, and within reasonable agreement, once the magnitude-weighting difference was accounted for, and given that the same seismic hazard model underpinned both hazards [14].

\section{This Study}

Circumstantial evidence from early applications suggested that the NZTA-BM and NZS1170.5 hazards provided substantially different $P G A$ values at some NZ locations. This unexpected inconsistency triggered the need for this study (presented in this paper), including site-specific PSHA (presented in the companion paper, Bradley et al., [1]), to resolve the $P G A$ hazard issues for the purpose of Revision 1 of the geotechnical guideline series.

In this paper, the $P G A$ hazard defined in current seismic provisions (NZS1170.5 and NZTA-BM) are comparatively examined for all NZ locations considered in NZS1170.5, to identify critical inconsistencies and key points of difference between the two provisions. Next, results from recent sitespecific PSHA at 24 locations across NZ [1] are used to scrutinise $P G A$ and $M$ characteristics in the NZTA-BM hazard, to identify locations at which significant anomalies occur, and also potential reasons for the inconsistencies. Finally, the $P G A$ hazard recommended as interim guidance for the geotechnical guideline series is presented. The paper highlights important considerations in the interpretation of the seismic hazard of NZ for engineering assessment and design, and hence initiates some timely considerations at the onset of the major study for an update of the NZ seismic hazard and its implementation into engineering practice.

\section{SEISMIC HAZARD IN CURRENT PROVISIONS IN NEW ZEALAND}

Currently, there are two codified versions of the seismic hazard of NZ that are used in the engineering practice: NZS1170.5 [10] and NZTA-BM $[11,12,13]$. NZS1170.5 is the structural loading standard, which focuses on structural applications and buildings in particular. NZTA-BM focuses on bridge structures, but also specifically addresses the design of retaining structures, embankments, slopes and soil liquefaction, all of which are outside the scope of NZS1170.5.

\section{Seismic Hazard in NZS1170.5}

The focus of NZS1170.5, in the context of this paper, is on the definition of appropriate spectra for structural loading (design). Elastic site hazard spectra, $C(T)$, are specified using the following expression:

$C(T)=C_{h}(T) \cdot Z \cdot R \cdot N$

where $C_{h}(T)$ is the spectral shape factor, which depends on the period and site subsoil class; $Z$ is the hazard factor; $R$ is the return period factor; and $N$ is the near-fault factor, which takes a value of 1.0 for $P G A$. The hazard factor, $Z$, used in NZS1170.5 is defined as [14]:

$Z=\frac{S_{a}(0.5 s)}{2}$

where $S_{a}(0.5 s)$ is the spectral acceleration at $0.5 \mathrm{~s}$ with return period of 500 years, for Site Class C, based on PSHA results at the time of the development of NZS1170.5 [14]. Hence, $R=1$ for a return period of 500 years, and scaling of the spectra for other return periods is performed using values for $R$ specified in Table 3.5 of NZS1170.5.

Figure 1 illustrates spectral shapes for site classes A, B and C. As $C_{h}(0.5 s)=2$ for Site Class C, the definition of the hazard factor in Equation (2) effectively states that the value of $Z$ is equal to the $P G A$ (in $\mathrm{g}$ ) for site classes $\mathrm{A}$ and $\mathrm{B}$ (rock), $P G A_{A, B}$ $=S_{a}(0 \mathrm{~s})$, for a return period of 500 years. Hence, even though the hazard factor $Z$ is nominally related to a particular spectral value, in fact $[14,10]$ :

$P G A_{A, B}=C_{h}(0 s) \cdot Z=1.0 \cdot Z$

The $P G A$ for other site classes is also related to $Z$ through respective amplification factors at $T=0 \mathrm{~s}$ :

$P G A_{C}=1.33 \cdot P G A_{A, B}$
$P G A_{D, E}=1.12 \cdot P G A_{A, B}$

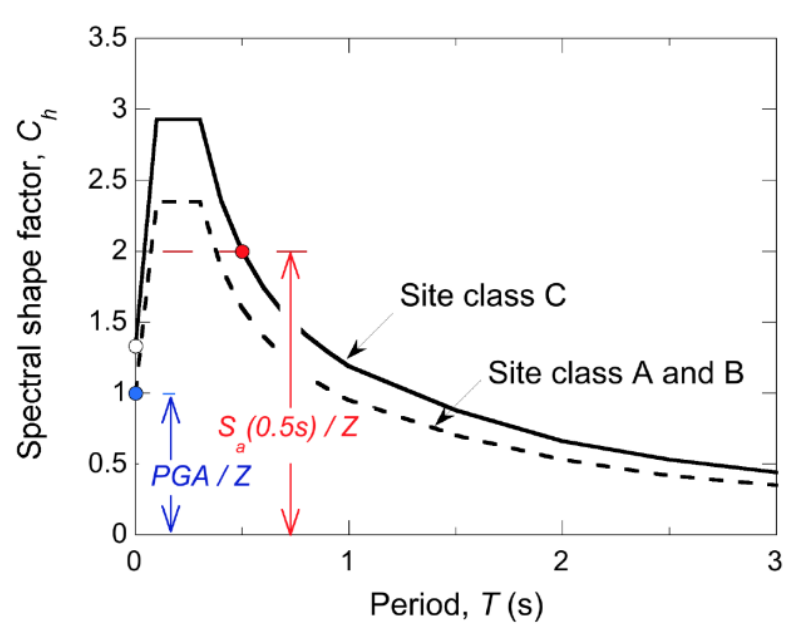

Figure 1: Relationship between spectral accelerations $C_{h}(0.5 s), P G A$ and $Z$ factor in NZS1170.5.

Importantly, the elastic spectra defined in NZS1170.5 are magnitude-weighted for a magnitude 7.5 earthquake [14]. Thus, the PGAs derived using Equations (3) to (5) in NZS1170.5 provide magnitude-weighted $P G A 7.5(N Z S)$ values.

In Table 3.3 of NZS1170.5, Z-values are tabulated for 129 locations in NZ. The hazard factor, $Z$, represents the only discriminating factor between the $P G A$ hazard of different locations across NZ. The hazard factor, $Z$, varies substantially across NZ, from 0.10 (as amended in 2016) to 0.60, in low and high seismicity regions, respectively. Note that $Z$ effectively controls the vertical position of the spectra $C(T)$, including $P G A$ $=S_{a}(0 \mathrm{~s})$. 


\section{Seismic Hazard in NZTA Bridge Manual}

NZTA-BM refers to two separate sets of hazard parameters: one for determination of structural loading (design), and the other for determination of seismic loads required in the assessment of slopes and liquefaction, and design of foundations, embankments and earth retaining structures. For brevity, we will refer to the latter set as parameters for geotechnical design.

For structural loading (design), the elastic site hazard spectra specified in NZS1170.5 are stipulated for use in NZTA-BM. There are differences in the definition of the minimum and maximum earthquake loads between NZTA-BM and NZS1170.5, including an allowance for limited modifications of the earthquake loading based on site-specific hazard studies in NZTA-BM. However, in essence, NZTA-BM uses the elastic site hazard spectra from NZS1170.5 to specify loads for structural design.

For geotechnical design, a separate hazard definition is stipulated, as summarised below. A $P G A$ value (in units of g) is determined for a relevant return period and Site Class A or B using the following expression:

$P G A_{A, B}=\frac{C_{0,1000(A, B)}}{1.3} R$

where $C_{0,1000(A, B)}$ is the 1000 -year return period $P G A$ coefficient (expressed in $g$ ) for a subsoil Class $\mathrm{A}$ or $\mathrm{B}$, and $R$ is the return period factor, as specified in Table 3.5 of NZS1170.5. Using $R$ $=1$, the $P G A$ for a return period of 500 years is obtained.

For Site Class $\mathrm{C}$, the $P G A$ is estimated as:

$P G A_{C}=1.33 \cdot P G A_{A, B}$

An equivalent expression to Equation (6) is also provided for Site Class D or E:

$P G A_{D, E}=\frac{C_{0,1000(D, E)}}{1.3} R$

where $C_{0,1000(D, E)}$ is the 1000 -year return period $P G A$ coefficient for a Site Class D or E.

In NZTA-BM, $P G A_{D, E}$ and $P G A_{A, B}$ are not parametrically related (through site class coefficients), but rather the $P G A s$ for the two site classes are considered separately. The values tabulated in Table C6.1 of NZTA-BM [13] yield the following correlation between $P G A_{D, E}$ and $P G A_{A, B}$ :

$P G A_{D, E}=f \cdot P G A_{A, B}$

where $f$ varies between 0.9 and 1.3 as a function of the intensity of the ground motion $\left(P G A_{A, B}\right)$. This aspect is explored in greater detail in the later sections of this paper.

In NZTA-BM [13], $C_{0,1000(A, B)}$ and $C_{0,1000(D, E)}$ values are tabulated (in Table C6.1) for a nearly identical set of locations as in NZS1170.5, which allows estimation of $P G A$ s for different site classes and return periods using Equations (6) to (8). Unlike NZS1170.5, the PGAs in NZTA-BM are not magnitudeweighted, but rather an earthquake magnitude (referred to as effective magnitude, $M_{\text {eff }}$ is specified for each return period. In other words, the seismic hazard for geotechnical design is defined using two parameters, a $P G A$ and $M_{\text {eff, which jointly }}$ specify the ground motion characteristics. In NZTA-BM, $P G A_{A, B}$ varies across NZ from $0.09 \mathrm{~g}$ to $0.50 \mathrm{~g}$, while the effective magnitudes range between 5.7 and 7.2. The exact definition of the effective magnitude is not specified in NZTABM.

\section{COMPARISON BETWEEN NZS1170.5 AND NZTA-BM PEAK GROUND ACCELERATIONS}

\section{Calculation of Magnitude-Weighted $P G_{7.5(N Z T A)}$ from NZTA-BM Hazard}

In order to rigorously compare the $P G A s$ specified in NZS1170.5 and NZTA-BM, one has to bring the two sets of $P G A$ s to a common basis for comparison. In fact, the only option for such comparison is the magnitude-weighted PGA7.5, which is the format of the PGA adopted in NZS1170.5, as the lack of detail on earthquake magnitudes in the NZS1170.5 hazard does not allow for any alternative presentation of that hazard. Hence, a procedure is summarised below that allows converting the PGA values of NZTA-BM (Table C6.1) into magnitude-weighted PGA7.5(NZTA) values, for a magnitude 7.5 earthquake.

In the development of the magnitude-weighted $P G A_{7.5(N Z S)}$ values in NZS1170.5 (via the hazard factor $Z$ ), a magnitude weighting was applied to the spectra for periods between $0 \mathrm{~s}$ and $0.5 \mathrm{~s}$ according to the method proposed by Idriss [15]. A Magnitude-Weighting Factor, $M W F=(M / 7.5)^{1.285}$ was applied in the calculation of $Z$, and thus effectively $P G A 7.5(N Z S)$, where $M$ is the earthquake magnitude, and the denominator 7.5 indicates that $M=7.5$ was used as a reference magnitude. The magnitude-weighting approach is well established in simplified liquefaction evaluation, and the concept behind it is briefly described in the Appendix.

A Magnitude-Scaling Factor (MSF), which is simply the inverse of $M W F$, is typically used in liquefaction evaluation. The magnitude scaling function of Equation (10) was used in the development of the NZS1170.5 hazard.

$M S F=\frac{1}{M W F}=\left(\frac{7.5}{M}\right)^{1.285}$

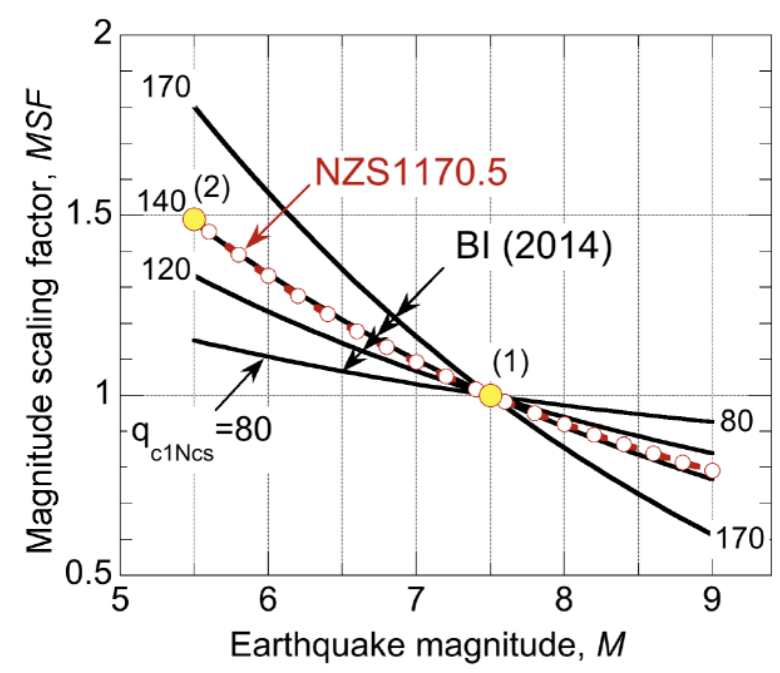

Figure 2: Magnitude scaling functions used in the development of the $Z$ factor in NZS1170.5 (white symbols with dashed line) and proposed in the liquefaction triggering procedure of Boulanger and Idriss [5] (solid lines for different $q_{c 1 N c s}$ values; $q_{c 1 N c s}$ is a normalised clean sand equivalent cone tip resistance); the larger yellow symbols refer to the discussion presented in the Appendix.

Using $M S F$ from Equation (10), which is illustrated in Figure 2, the PGAs from NZTA-BM can be easily converted into equivalent magnitude-weighted values, $P G A 7.5(N Z T A)$, with the following expression:

$P G A_{7.5(N Z T A)}=P G A \cdot M S F=P G A \cdot\left(\frac{7.5}{M_{e f f}}\right)^{1.285}$ 
where $P G A$ is a peak ground acceleration determined in NZTA$\mathrm{BM}$, as summarised by Equations (6) to (8), and $M_{\text {eff }}$ is the corresponding effective magnitude specified in NZTA-BM (Table C6.1), for the particular return period at the location of interest. The PGA7.5(NZTA) values calculated using Equation (11) can be directly compared to the respective $P G A 7.5(\mathrm{NZS})$ values for each location, which is the focus of the subsequent section.

\section{Comparison between PGA7.5(NZTA) and PGA7.5(NZS)}

Ratios of magnitude-weighted PGAs, PGA7.5(NZTA)/PGA7.5(NZS) are depicted in Figure 3 for 120 locations (from the total of 129 locations) listed in NZS1170.5 (Table 3.3) for which hazard values were also tabulated in NZTA-BM. Two sets of ratios are shown, for Site Class C and D, respectively, both for PGAs with a return period of 500 years. Note that the numbering of locations generally goes from north towards south, from Kaitaia to Invercargill. The locations of several urban centres are indicated in the figure for reference.

The comparison in Figure 3 shows that $P G A_{7.5(N Z T A)}$ values are consistently lower than $P G A 7.5(\mathrm{NZS})$, with the mean $P G A_{7.5(\mathrm{NZTA})}$ value being approximately $20 \%$ lower than the respective $P G A 7.5$ (NZS) value. There is an apparent regional fluctuation of $P G A 7.5$ (NZTA)/PGA7.5(NZS) where locations in the same region have generally similar ratios, though deviations from this trend are also evident. In the extreme cases, $P G A 7.5($ NZTA) values are up to $40 \%$ lower than the $P G A 7.5(N Z S)$ values.

Figure 4a shows no correlation between the ratio

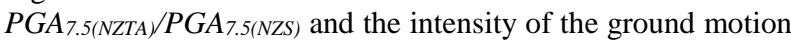
$\left(P G A_{(N Z T A)}\right)$. A similar lack of correlation is also evident in Figure $4 \mathrm{~b}$ when plotting $P G A 7.5$ (NZTA)/PGA7.5(NZS) against the effective magnitude $\left(M_{e f f}\right)$. Hence, no clear trend is observed in the differences between $P G A 7.5$ resulting from NZTA-BM and NZS1170.5 hazards with ground-motion characteristics (PGA $A_{N Z T A}$ and $\left.M_{\text {eff }}\right)$.

\section{SCRUTINY OF CODIFIED HAZARDS USING SITE- SPECIFIC PSHA}

The comparisons between $P G A_{7.5(N Z T A)}$ and $P G A_{7.5(N Z S) \text {, }}$ summarised in Figure 3, show substantial differences between the NZTA-BM and NZS1170.5 PGA hazards even when the effects of magnitude scaling are accounted for. To further investigate these differences in the $P G A$ hazard, an additional seismic hazard study was conducted in support of Revision 1 of the geotechnical modules, in which site-specific PSHA was performed at selected locations. Details of this most recent hazard study are presented in the companion paper [1], whereas herein a summary of its most important features and outcomes are discussed.

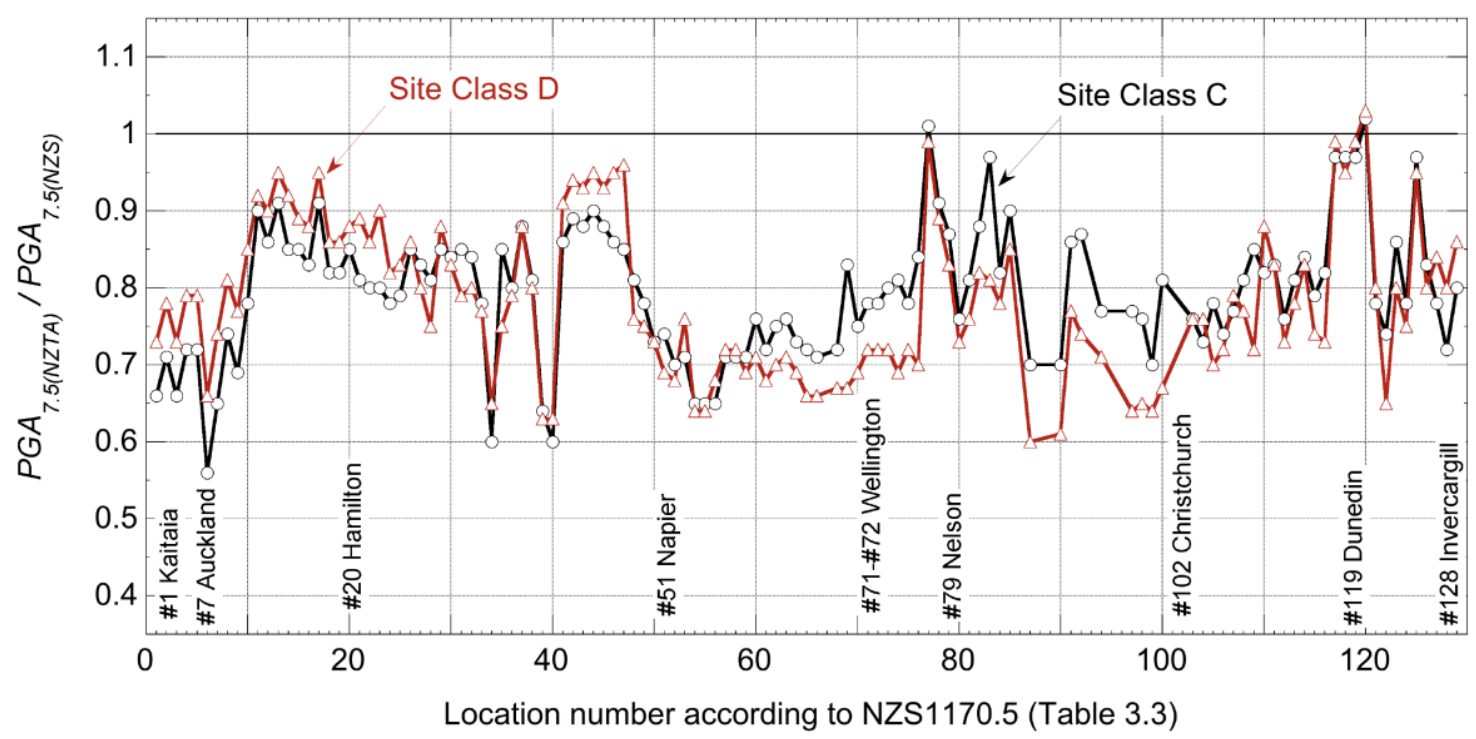

Figure 3: Comparison of magnitude-weighted PGA7.5 values of hazards presented in NZTA Bridge Manual and NZS1170.5, in terms of ratio, for 120 locations across NZ; the PGA7.5 values are for 500-year return period, for Site Class $C$ and $D$.
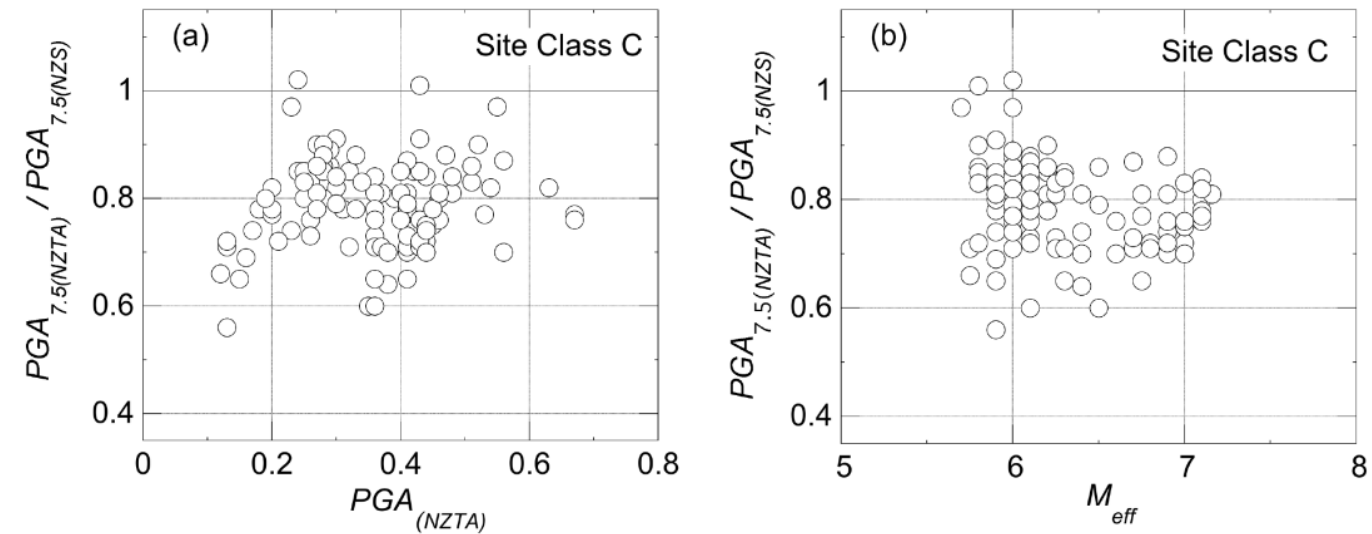

Figure 4: Magnitude-weighted ratios PGA7.5(NZTA)/ PGA7.5(NZS) for 120 NZ locations as a function of ground motion characteristics: (a) peak ground acceleration in NZTA-BM (PGA $($ NZTA)); (b) earthquake magnitude in NZTA-BM (Meff). 


\section{Site-specific PSHA}

Site-specific PSHA was performed at 24 locations which were carefully selected to include: (i) locations for which

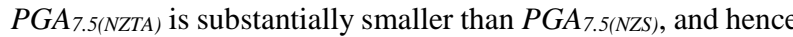
$P G A 7.5$ (NZTA) could be potentially unconservative (i.e., underestimating the hazard); (ii) major urban centres of NZ, which have a high exposure of people and assets, and hence high risk associated with seismic hazards; and (iii) regional centres to achieve relatively uniform spatial coverage across NZ including high, moderate and low seismicity areas. The locations where site-specific PSHA was undertaken are superimposed on a fault map of NZ in Figure 5 to illustrate their distribution across NZ and proximity to known major earthquake sources.

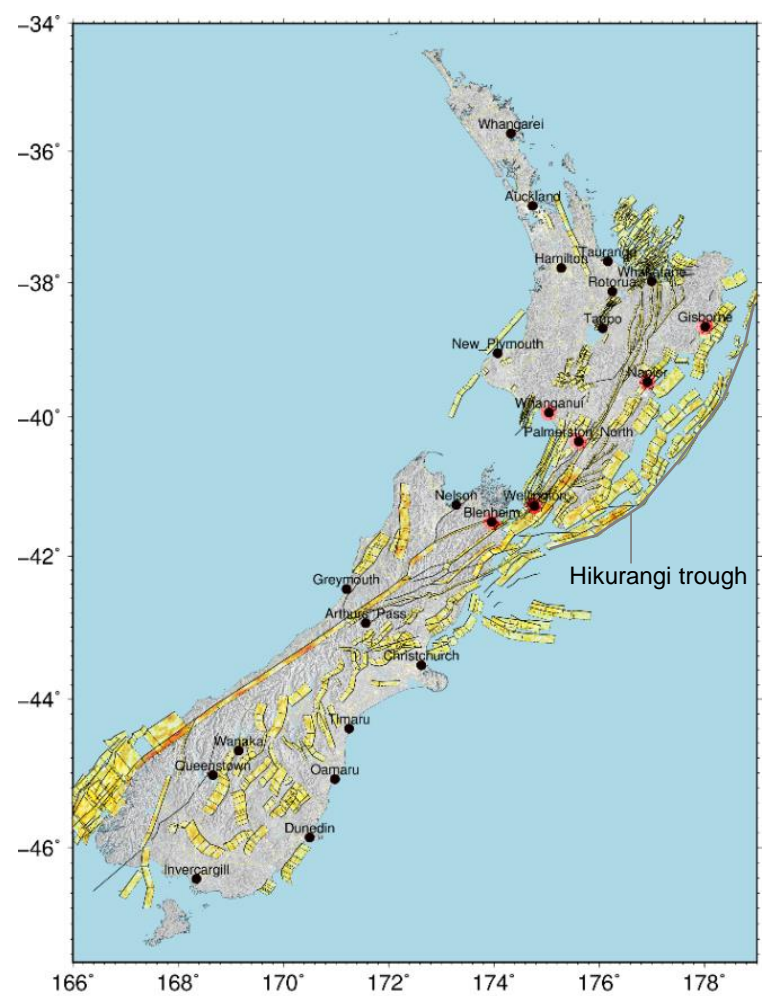

Figure 5: Locations for site-specific PSHA superimposed on a fault map of $\mathrm{NZ}$ with the six principal locations shown with a red shadow; faults are those defined in Stirling et al. [16].

Site-specific PSHA was performed using a seismic source model based on Stirling et al. [16], with a logic tree approach to account for ground motion model (GMM) uncertainty. Four active shallow crustal GMMs and two subduction models were employed [1]. PSHA was performed at each location for two reference site conditions of $V_{s, 30}=200$ and $300 \mathrm{~m} / \mathrm{s}$, which roughly correspond to Site Class D and Site Class C respectively in the NZ site classification scheme specified in NZS1170.5 (where $V_{s, 30}$ is the time-averaged shear wave velocity over the upper $30 \mathrm{~m}$ ). Justification of the above assumptions and details of PSHA are given in [1].

For each location, $P G A$ hazard curves were computed, for $V_{s, 30}$ $=200$ and $300 \mathrm{~m} / \mathrm{s}$, and the corresponding $P G A$ values at return periods $(R P)$ of $25,50,100,250,500,1000$ and 2500 years were obtained. Example hazard curves for Gisborne and Auckland are shown in Figure 6, where RPs are also indicated. A large difference is evident between the $P G A$ hazards for Gisborne and Auckland, as the two sets of results are representative of relatively high and low seismicity areas in NZ. In addition to the hazard curves, disaggregation results from site-specific PSHA are also presented for each location, for $R P=25$ and 500 yr, including respective mean magnitudes $\bar{M}$ in Bradley et al. [1].

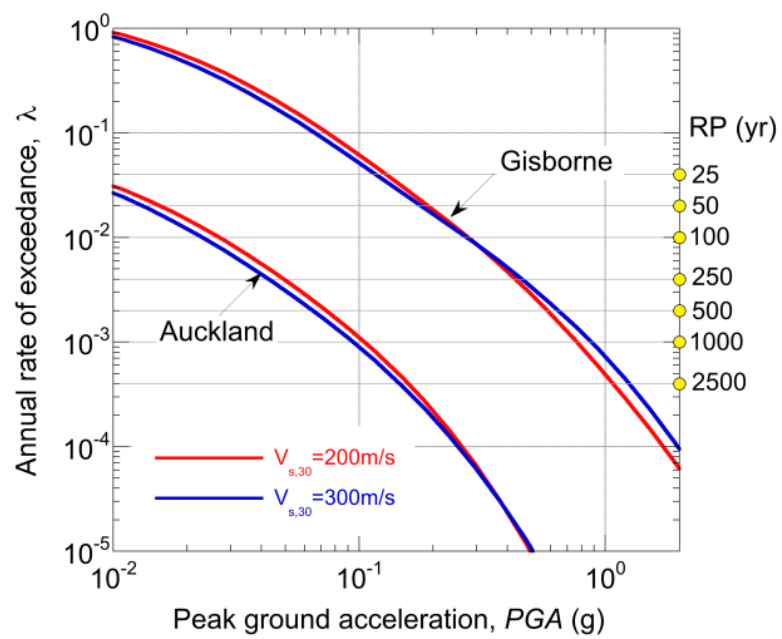

Figure 6: PGA hazard curves from site-specific PSHA for Gisborne and Auckland, for $V_{s, 30}=200$ and $300 \mathrm{~m} / \mathrm{s}$.

Using the $P G A$ and mean magnitude $\bar{M}$ values obtained from site-specific PSHA, PGA7.5(SS-PSHA) values were calculated for each location according to the following expression:

$P G A_{7.5(S S-P S H A)}=P G A \cdot M S F_{140} \approx P G A \cdot\left(\frac{7.5}{\bar{M}}\right)^{1.285}$

where $M S F_{140}$ is the magnitude scaling factor of Boulanger and Idriss [5] for $q_{c l N c s}=140$. As shown in Figure 2 and implied by Equation (12), $M S F_{140}$ is practically identical with the magnitude scaling embodied in NZS1170.5 and used previously in the conversion of $P G A$ values of NZTA-BM into an equivalent magnitude-weighted $P G A_{7.5 \text { (NZTA) (i.e., Equations }}$ 10 and 11). Hence, the computed PGA7.5(SS-PSHA) from sitespecific PSHA is directly comparable to PGA7.5(NZTA) and $P G A 7.5(N Z S)$ at respective locations.

\section{Comparisons between Site-specific PSHA and NZTA-BM PGA 7.5 Hazards}

In the comparative plots that follow, results for only 23 sites are shown, as the PGA hazard for Christchurch is stipulated via CER guidance $[17,18]$. Hence, results for Christchurch are not included in the comparisons. Figure 7 a shows $P G A 7.5(\mathrm{SS}$ ${ }_{P S H A} / P G A_{7.5(N Z T A)}$ ratios for the 23 locations for which sitespecific PSHA was performed, for $V_{s, 30}=300 \mathrm{~m} / \mathrm{s}\left(P G A_{7.5}(S S\right.$. $P S H A)$ ) or Site Class C $(P G A 7.5(N Z T A))$, and for $R P=500$ yr. For approximately two-thirds of the locations, the ratio PGA7.5(SS_PSHA)/PGA7.5(NZTA) is less than one, implying PGA7.5(SSPSHA) < PGA7.5(NZTA). Specifically, for 15 locations $(63 \%$ of the investigated sites), $P G A_{7.5(S S-P S H A)} / P G A_{7.5 \text { (NZTA })}<0.9$, out of which for 13 locations PGA7.5(SS-PSHA) is $60 \%$ to $90 \%$ of the PGA7.5(NZTA) value, and for two sites (Auckland and Whangarei), $P G A 7.5$ (SS-PSHA) is $40 \%$ or less of $P G A_{7.5(N Z T A)}$. For two locations (Whakatane and Taupo), PGA7.5(SS-PSHA) is either similar or slightly higher (5\% to $10 \%$ ) than $P G A 7.5(N Z T A)$. The 15 locations for which PGA7.5(SS_PSHA) from site-specific PSHA is smaller than $P G A 7.5$ (NZTA) are geographically constrained in the western and northern parts of the North Island, while they are spread across the South Island.

In contrast, for six locations, $P G A_{7.5(S S-P S H A)}$ is significantly higher than $P G A 7.5(N Z T A)$, i.e., approximately $35-45 \%$ higher for Whanganui, Blenheim, Napier and Palmerston North, and then $70 \%$ to $110 \%$ higher for Wellington and Gisborne. Clearly, there are significant differences between the $P G A$ hazards from site-specific PSHA and NZTA-BM, and especially important 
are the differences for the six locations for which NZTA-BM hazard substantially underestimates the $P G A$ hazard relative to site-specific PSHA.

Figure $7 \mathrm{~b}$ comparatively shows the mean magnitude $\bar{M}$ from site-specific PSHA at 23 locations (solid symbols) and effective magnitude $M_{\text {eff }}$ from NZTA-BM for 120 locations (open symbols). $M_{\text {eff }}$ and $\bar{M}$ are in reasonable agreement for most of the investigated locations; however, there are considerable differences between $M_{\text {eff }}$ and $\bar{M}$ for the six locations for which PGA7.5(SS-PSHA) $\gg P G A 7.5$ (NZTA). For these sites, $\bar{M}$ is significantly higher than $M_{\text {eff. }}$. Note that the symbols for the six locations are encircled by large red open-symbols in Figure 7, a notation that will be often used in figures to indicate these locations. For the six locations, $\bar{M}=6.9-7.7$ whereas $M_{\text {eff }}=$ 6.0 - 7.1. The larger earthquake magnitude obtained in sitespecific PSHA is one of the contributing factors to the higher values of PGA7.5(SS-PSHA) as compared to PGA7.5(NZTA), at these locations. Bradley et al. [1] provide further information on seismic hazard disaggregation, which illustrates the contributing earthquake ruptures to the PSHA results.

Figure 8 allows further scrutiny of the $P G A$ hazards through a direct comparison between PGA7.5(SS-PSHA) and PGA7.5(NZTA) (Fig. 8a), and the observed correlation between PGA7.5(SS-PSHA) and $\bar{M}$ for the site-specific hazard (Fig. 8b). It is evident in
Figure 8a, that $P G A 7.5$ (NZTA) generally overestimates the hazard for locations with $P G A 7.5<0.30 \mathrm{~g}$ (relatively low and moderate seismicity regions), and conversely, PGA7.5(NZTA) underestimates the hazard for locations with $P G A_{7.5}>0.30 \mathrm{~g}$ (i.e., high seismicity regions). The underestimation of the hazard increases with increasing $P G A$, and is the highest for Wellington and Gisborne where PGA7.5(SS-PSHA) exceeds $0.60 \mathrm{~g}$.

In Figure 8, large red open-symbols are used to indicate the hazard values for the six locations with $P G A 7.5$ (SS-PSHA) $\gg$ $P G A_{7.5(N Z T A)}$. It is apparent that these locations are in highseismicity regions with $P G A 7.5$ (SS-PSHA) $>0.5 \mathrm{~g}$ and $\bar{M}>7$, with one exception. However, the key discriminating feature that sets apart these six locations from the remaining 17 locations, is that there is a significant contribution of the Hikurangi Subduction Zone (HSZ) in their aggregated hazard. For each of these six sites, the contribution of the HSZ to the total hazard is from $30 \%$ to $50 \%$, and importantly, the source-to-site distance specific to HSZ is relatively short, mostly within $20-40 \mathrm{~km}$, and only about $20 \mathrm{~km}$ for two of the locations (Wellington and Gisborne). The proximity of the six locations to the HSZ is evident in Figure 5. The shaded area in Figure 8a illustrates the deviation from the general trend in PGA7.5(NZTA) for locations affected by the HSZ.
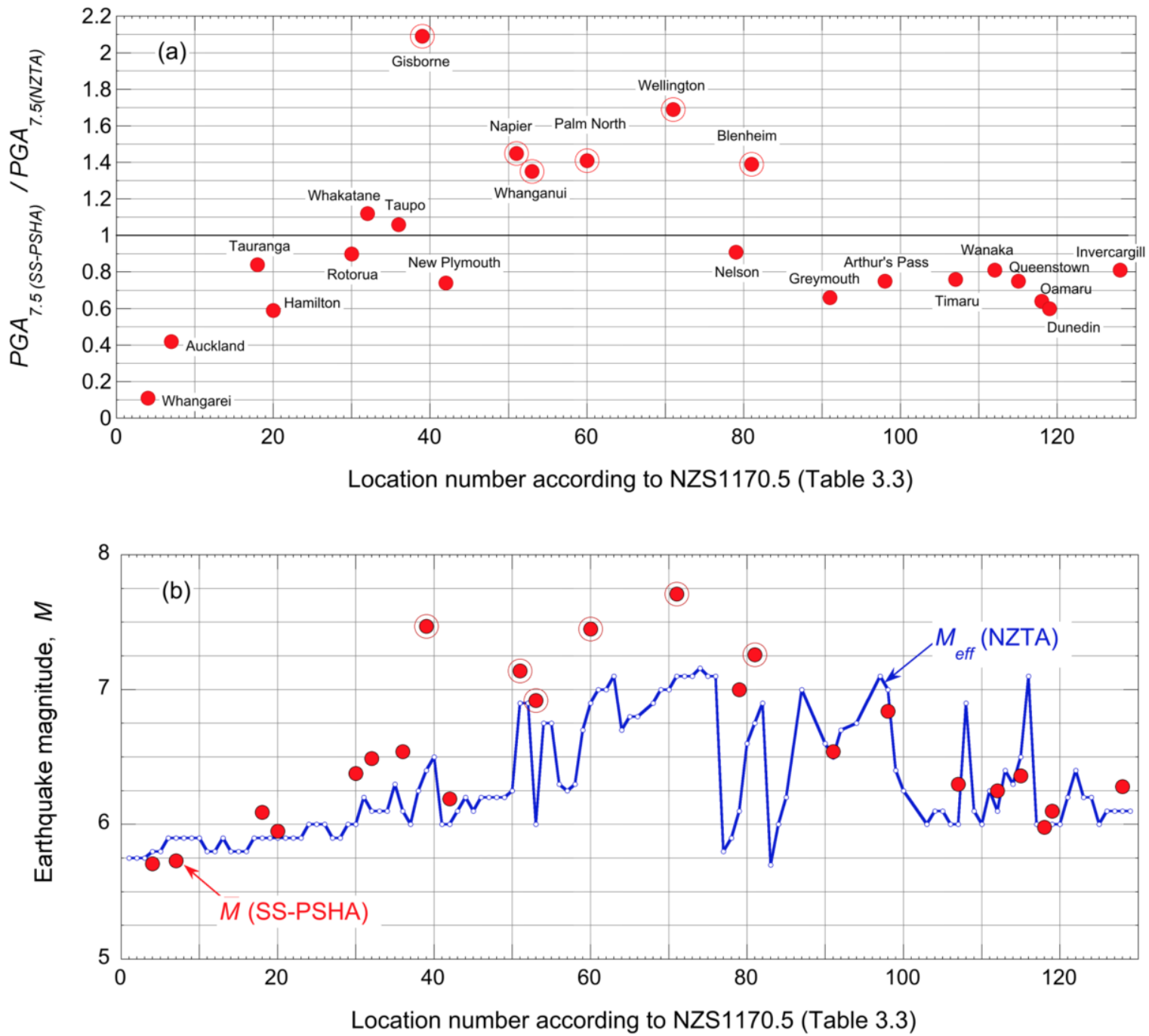

Figure 7: Comparison of magnitude-weighted PGA7.5 hazards obtained from NZTA-BM and site-specific PSHA for RP=500 yr, for Site Class $C$ or $V_{s, 30}=300 \mathrm{~m} / \mathrm{s}$ : (a) PGA 7.5 (SS-PSHA)/PGA7.5(NZTA) ratios; (b) earthquake magnitude (Meff and $\bar{M}$ ); Note: data for Christchurch is not shown as PGA hazard is stipulated via CER guidance [17,18]. 

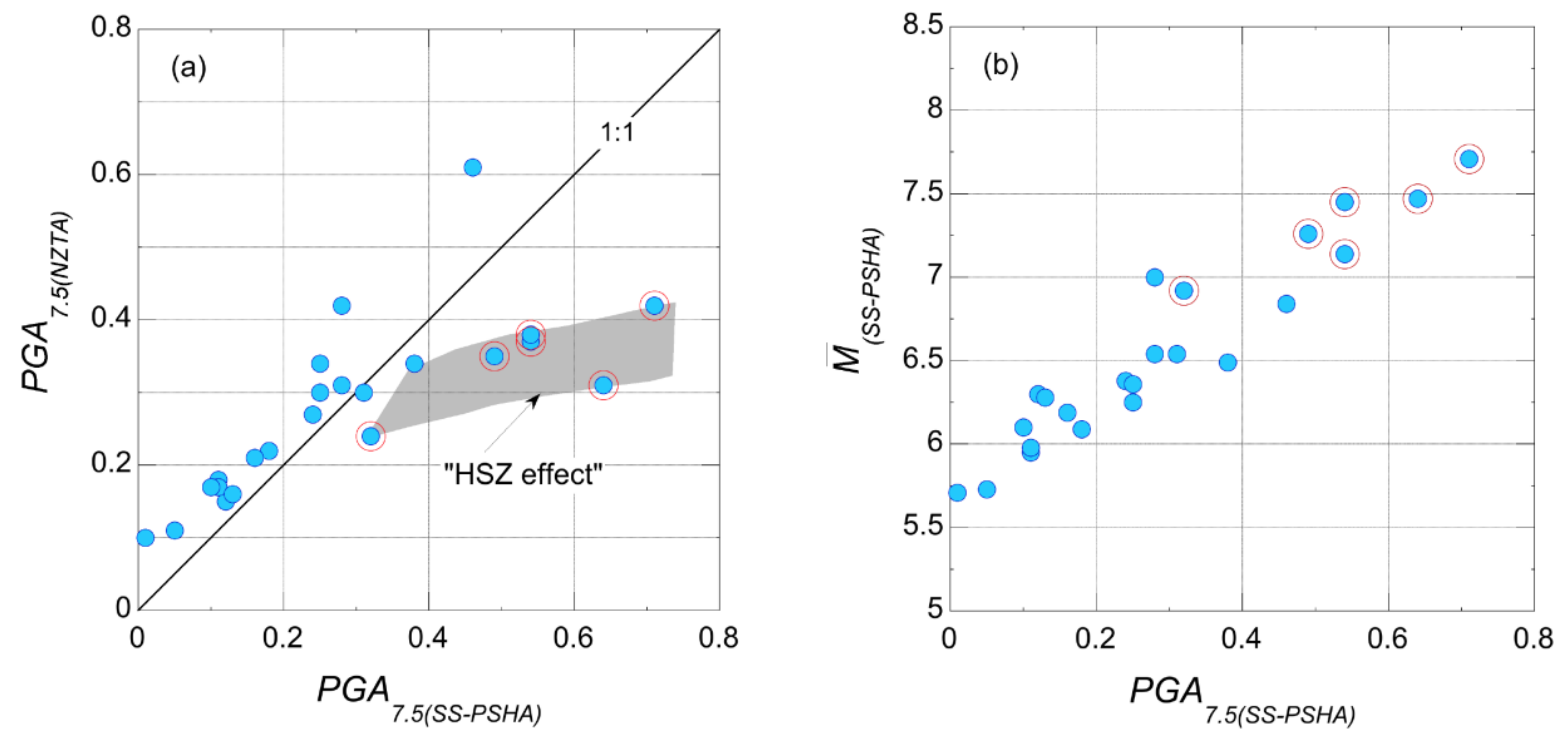

Figure 8: Effects of ground motion intensity and earthquake magnitude on PGA 7.5: (a) direct comparison between PGA 7.5(SS-PSHA) and PGA 7.5(NZTA); (b) correlation between PGA7.5(SS-PSHA) and $\bar{M}$ from site-specific PSHA.

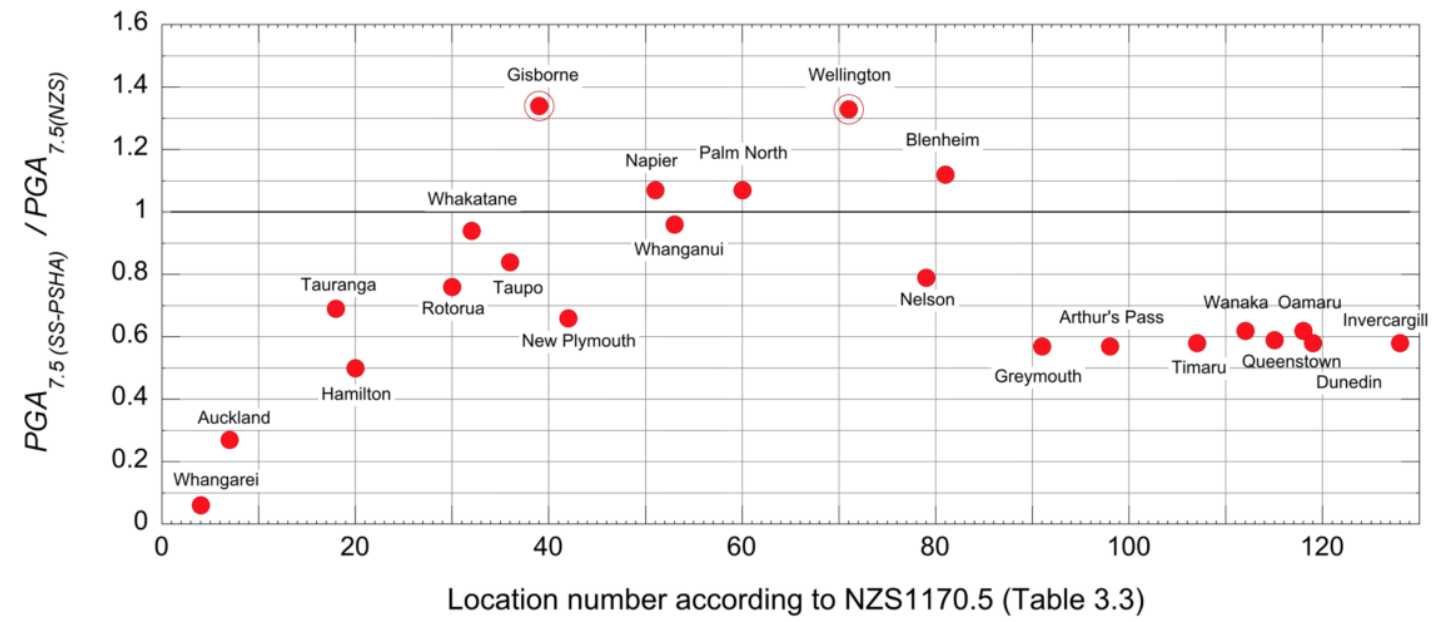

Figure 9: Comparison of magnitude-weighted PGA7.5(NZS) values from the hazard presented in NZS1170.5 and site-specific $P G A 7.5(S S-P S H A)$ values for $R P=500 y r$, for Site Class $C(N Z S 1170.5)$ or $V_{s, 30}=300 \mathrm{~m} / \mathrm{s}$, respectively; Note: data for Christchurch is not shown as PGA hazard is stipulated via CER guidance [17,18].

\section{Comparisons between Site-specific PSHA and NZS1170.5 Hazards}

Figure 9 shows the PGA7.5(SS-PSHA)/PGA7.5(NZS) ratios for the 23 locations, for $V_{s, 30}=300 \mathrm{~m} / \mathrm{s}(P G A 7.5($ SS-PSHA) $)$ or Site Class C $(P G A 7.5(N Z S))$ and $R P=500$ yr. For 18 locations, i.e., $\sim 80 \%$ of the locations subject to site-specific PSHA, PGA7.5(SS-PSHA) is lower than $P G A_{7.5(\mathrm{NZS})}$; for three locations $P G A_{7.5 \text { (SS-PSHA) is }}$ slightly higher (5-10\%); and for two locations (Wellington and Gisborne), $P G A 7.5(S S-P S H A)$ is substantially higher (30-35\%) than $P G A 7.5(N Z S)$.

A direct comparison between $P G A 7.5($ SS-PSHA) and $P G A 7.5(\mathrm{NZS})$ is shown in Figure 10, where it is apparent that $P G A_{7.5(\mathrm{NZS})}$ is generally overestimating the hazard for $P G A 7.5<0.40 \mathrm{~g}$, but substantially underestimating the hazard for the two locations with $P G A 7.5>0.60 \mathrm{~g}$. Note that the latter applies to locations that are in close proximity to the HSZ, and for which the HSZ has a significant contribution to the total $P G A$ hazard.

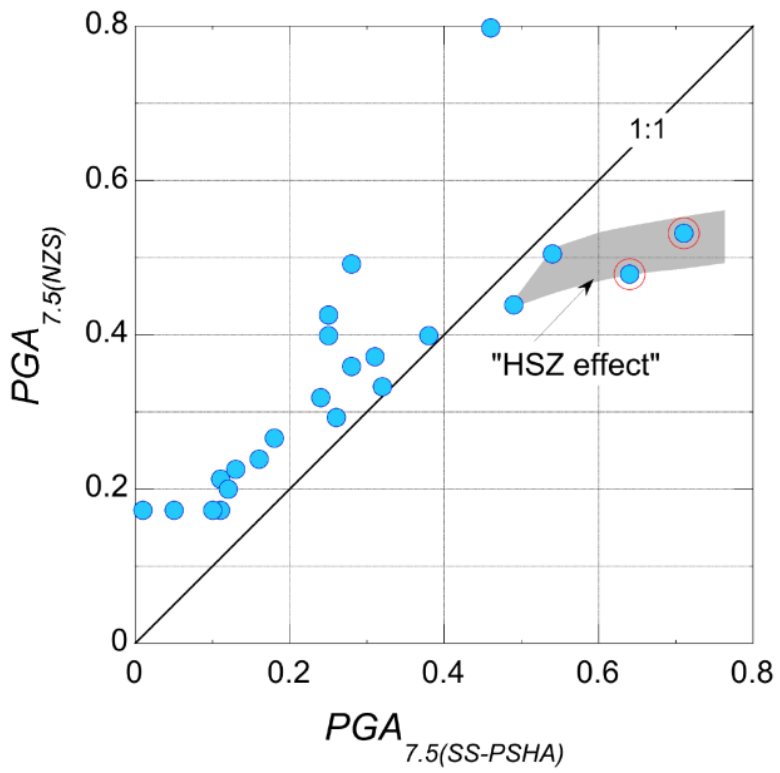

Figure 10: Correlation between PGA7.5(NZS) from NZS1170.5 and PGA7.5(SS-PSHA) from site-specific PSHA at 23 investigated locations. 


\section{RECOMMENDED INTERIM HAZARD FOR GEOTECHNICAL ASSESSMENT AND DESIGN}

As current Revision 0 of the geotechnical guidelines refers to the NZTA-BM hazard (PGA and $M_{\text {eff }}$ values), it is considered appropriate to continue the use of the NZTA-BM hazard for most of the NZ locations, but address the anomalies in the NZTA-BM hazard identified from the site-specific PSHA presented in the previous section and in Bradley et al. [1]. The hazard interpretation presented in Revision 1 of Module 1 of the geotechnical guidelines [19], and in this paper, is recommended for interim use until results from a comprehensive seismic hazard update for NZ are available. This approach, on one hand intends to maintain the continuity and stability in the seismic hazard used for seismic design, where appropriate, but on the other hand, also aims to address major anomalies in the NZTA$\mathrm{BM}$ hazard that significantly underestimate the $P G A$ hazard, for some NZ locations and their associated regions. Key elements of the interim hazard for geotechnical assessment and design are given below, whereas further details can be found in Module 1 (Revision 1) of the guideline series [19].

\section{Updated Hazard for Six Locations and Their Associated Regions}

For the six locations, at which $P G A_{7.5(N Z T A)}$ is significantly underestimated, $P G A$ and $\bar{M}$ values obtained from sitespecific PSHA [1] are recommended. Table 1 summarises the $P G A$ and $\bar{M}$ values for $V_{s, 30}=300 \mathrm{~m} / \mathrm{s}$, for $R P=25,50,100$, $250,500,1000$ and $2500 \mathrm{yr}$, for these locations. Note that the $P G A$ values were explicitly calculated for each $R P$, while $\bar{M}$ values were explicitly calculated only for $R P=25$ and $500 \mathrm{yr}$. $\bar{M}$ values between 25 and $500 \mathrm{yr}$ were interpolated using the following expression:

$M\left(R P_{i}\right)=M(25 y r)+[M(500 y r)-M(25 y r)] \frac{\ln \left(R P_{i} / 25\right)}{\ln (500 / 25)}$

in which $R P_{i}$ indicates an interpolated $R P$ in the range between 25 and $500 \mathrm{yr} . \bar{M}$ values for $R P>500 \mathrm{yr}$ were assumed constant and equal to $\bar{M}$ for $R P=500 \mathrm{yr}$. The appropriateness of the above interpolation was independently checked for the Wellington site-specific PSHA results.

For each of the six locations (referred to in the following as principal locations), neighbouring regions (locations) were identified that have similar hazard with the related principal location. These neighbouring locations typically have $P G A$ values within $5-10 \%$ difference and $M_{\text {eff }}$ within $0.1-0.2$ difference from their related principal location in the NZTABM hazard. Similarly, neighbouring locations are within 5-10\% difference in PGA7.5(NZS) from the related principal location in the NZS1170.5 hazard. In Figure 11, the six principal locations for which the hazard was updated according to Table 1 are indicated with different solid symbols which are encircled by large red open-symbols. Related neighbouring locations are depicted with the same solid symbol used for their reference principal location. Hence, Figure 11 visualises regions for which the hazard in NZTA-BM was updated based on sitespecific PSHA results, as summarised in Table 1. A full list of principal and associated neighbouring locations with $P G A$ and $\bar{M}$ values for $R P=25,50,100,250,500,1000$ and $2500 \mathrm{yr}$ are provided in Module 1 of the geotechnical guidelines [19].

For all locations other than those discussed above, the NZTABM hazard values for Site Class $\mathrm{C}$ have been adopted in Module 1 [19], with the exception of the Canterbury Earthquake Region, for which the hazard was stipulated by an interim MBIE guidance after the Canterbury Earthquake Sequence $[17,18]$.

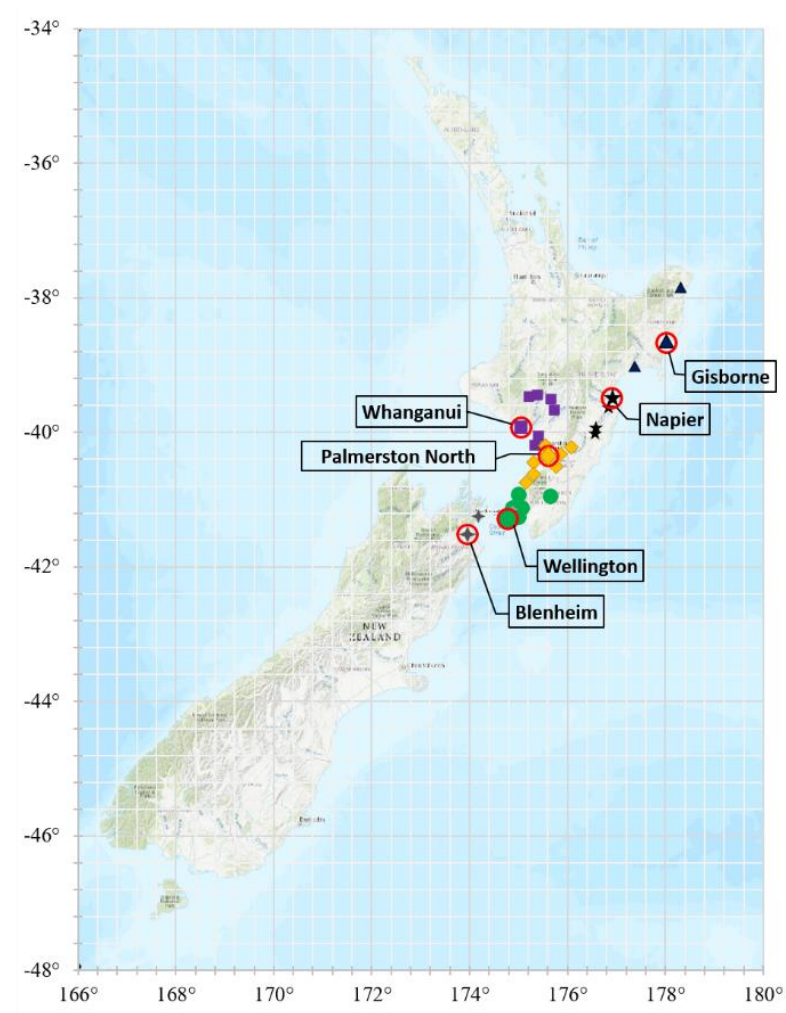

Figure 11: Six principal locations (encircled symbols) and their associated regions (locations) that share identical hazard (and same symbol) with their reference principal location.

Table 1: Summary of PGA and $\bar{M}$ values for six locations, for $V_{s, 30}=300 \mathrm{~m} / \mathrm{s}$ and $R P=25$ to $2500 y$.

\begin{tabular}{|c|c|c|c|c|c|c|c|c|c|c|c|c|c|c|}
\hline \multirow{3}{*}{ Location } & \multicolumn{14}{|c|}{ Return Period $(R P)$} \\
\hline & \multicolumn{2}{|c|}{$25 \mathrm{yr}$} & \multicolumn{2}{|c|}{$50 \mathrm{yr}$} & \multicolumn{2}{|c|}{$100 \mathrm{yr}$} & \multicolumn{2}{|c|}{$250 \mathrm{yr}$} & \multicolumn{2}{|c|}{$500 \mathrm{yr}$} & \multicolumn{2}{|c|}{$1000 \mathrm{yr}$} & \multicolumn{2}{|c|}{$2500 \mathrm{yr}$} \\
\hline & $\begin{array}{c}P G A \\
(g)\end{array}$ & $M$ & $\begin{array}{c}P G A \\
(g)\end{array}$ & $M$ & $\begin{array}{c}P G A \\
(g)\end{array}$ & $M$ & $\begin{array}{c}P G A \\
(g)\end{array}$ & $M$ & $\begin{array}{c}P G A \\
(g)\end{array}$ & $M$ & $\begin{array}{c}P G A \\
(g)\end{array}$ & $M$ & $\begin{array}{c}P G A \\
(g)\end{array}$ & $M$ \\
\hline Gisborne & 0.12 & 6.3 & 0.18 & 6.6 & 0.28 & 6.8 & 0.46 & 7.2 & 0.65 & 7.5 & 0.87 & 7.5 & 1.20 & 7.5 \\
\hline Wellington & 0.13 & 6.5 & 0.19 & 6.8 & 0.28 & 7.1 & 0.47 & 7.5 & 0.68 & 7.7 & 0.91 & 7.7 & 1.27 & 7.7 \\
\hline Palmerston North & 0.13 & 6.4 & 0.18 & 6.6 & 0.27 & 6.9 & 0.41 & 7.3 & 0.55 & 7.5 & 0.72 & 7.5 & 1.00 & 7.5 \\
\hline Napier & 0.12 & 6.4 & 0.18 & 6.5 & 0.26 & 6.7 & 0.42 & 7.0 & 0.58 & 7.1 & 0.78 & 7.1 & 1.11 & 7.1 \\
\hline Whanganui & 0.09 & 6.2 & 0.13 & 6.4 & 0.18 & 6.5 & 0.27 & 6.8 & 0.36 & 6.9 & 0.46 & 6.9 & 0.62 & 6.9 \\
\hline Blenheim & 0.12 & 6.4 & 0.18 & 6.6 & 0.26 & 6.8 & 0.39 & 7.1 & 0.52 & 7.3 & 0.67 & 7.3 & 0.90 & 7.3 \\
\hline
\end{tabular}

Note that the reported values are as calculated in site-specific PSHA; rounding of values might be adopted in [19] for simplification. 


\section{Site-Class Independent PGA Hazard}

The $P G A$ and $\bar{M}$ values presented in Table 1 are for $V_{s, 30}=$ $300 \mathrm{~m} / \mathrm{s}$, or Site Class C, according to the NZ classification scheme. In Module 1 , these $P G A$ and $\bar{M}$ values are recommended to be applied to all site classes without any modification, thus assuming $P G A_{A, B}=P G A_{C}=P G A_{D, E}$. The reasoning and evidence behind this recommendation is discussed below.

Figure 12 shows $P G A_{\left(V_{s 2} 20\right)} / P G A_{\left(V_{s} 300\right)}$ ratios plotted against $P G A_{(V s 300)}$, for all 24 sites for which site-specific PSHA was performed [1]. Here, $P G A_{\left(V_{s 2} 20\right)}$ and $P G A_{\left(V_{s} 300\right)}$ denote $P G A$ for $V_{s, 30}=200 \mathrm{~m} / \mathrm{s}$ and $300 \mathrm{~m} / \mathrm{s}$ respectively. As discussed earlier, $V_{s, 30}=200$ and $300 \mathrm{~m} / \mathrm{s}$ roughly correspond to Site Class D and Site Class C respectively in the site classification specified in NZS1170.5. The figure shows a consistent relationship for all sites in which $P G A_{V_{s} 200}$ is approximately $10-15 \%$ higher than $P G A_{V s 300}$ for low-intensity ground motions, when $P G A<0.10$ g. $P G A_{V s 200}$ is similar to $P G A_{V s 300}$ for $P G A$ in the range 0.30 0.45 g. Finally, $P G A_{V_{s} 200}$ is $10-15 \%$ lower than $P G A_{V_{s} 300}$ for high-intensity ground motions, when $P G A>0.60 \mathrm{~g}$. This trend is consistent with larger site amplification of accelerations at softer sites $\left(V_{s, 30}=200 \mathrm{~m} / \mathrm{s}\right)$ for low-amplitude ground motions. Conversely, a larger reduction in accelerations is seen in the case of high-intensity ground motions, due to more pronounced effects of soil nonlinearity for $V_{s, 30}=200 \mathrm{~m} / \mathrm{s}$ sites, as compared to stiffer $V_{s, 30}=300 \mathrm{~m} / \mathrm{s}$ sites.

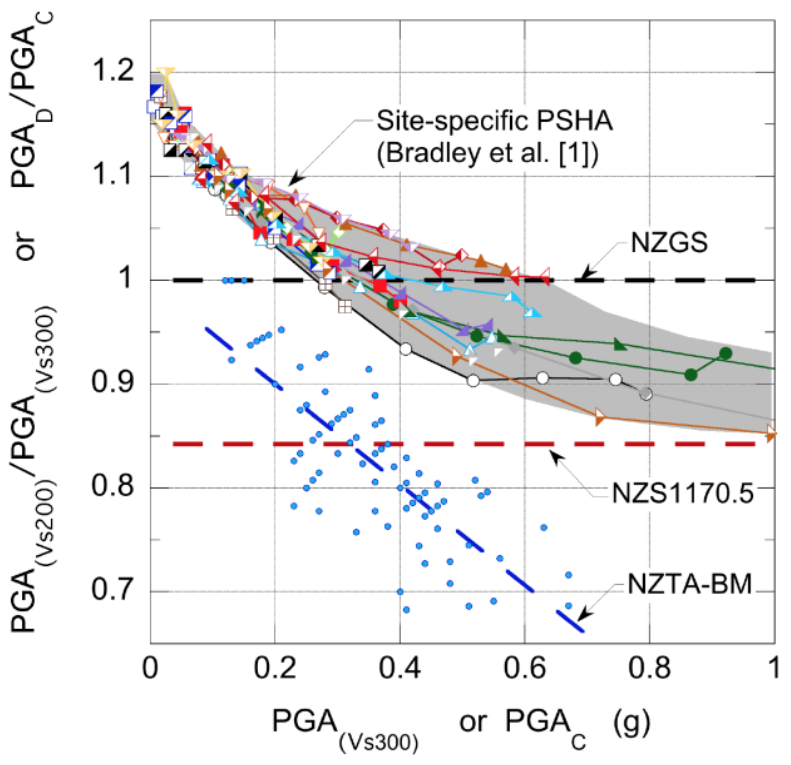

Figure 12: PGA $A_{\left(V_{s 200}\right)} / P G A_{(V s 300)}$ ratios plotted against $P G A_{(V s 300)}$ for $24 \mathrm{NZ}$ sites for which site-specific PSHA was performed $\left(R P=500\right.$ yr); respective $P G A_{D} / P G A_{C}$ relationships from NZTA-BM and NZS1170.5 hazards are also shown.

It is customary in provisions for seismic design of engineering structures to use constant amplification factors when correlating different site classes. For example, NZS1170.5 specifies amplification factors 1.33 and 1.12 for Site Class $\mathrm{C}$ and Site Class D or E, respectively, in relation to a reference Site Class A or B (rock), as illustrated by Equations (4) and (5). This yields a constant ratio $P G A_{D, E} / P G A_{C}=1.12 / 1.33=0.84$, which is shown as a horizontal dashed line in Figure 12. As described earlier in the discussion of Equations (6) to (9), NZTA-BM does not provide a direct correlation between $P G A_{D, E}$ and $P G A_{C}$ values, but it effectively employs a constant amplification factor of 1.33 for Site Class C relative to $P G A_{A, B}$ (Equation (7)), and a $P G A$-dependent amplification factor for Site Class D (Equation (9)). The resulting correlation between $P G A_{D, E} /$
$P G A_{C}$ and peak ground acceleration, derived based on all sites considered in NZTA-BM, is shown as an inclined dashed line in Figure 12, where it is evident that the NZTA correlation is positioned well-below the relationship obtained from sitespecific PSHA.

Figure 12 clearly demonstrates that neither NZTA-BM nor NZS1170.5 provide an appropriate ratio between the peak ground accelerations of Site Class C and Site Class D or E conditions. Indeed, if the simplest form of correlation between $P G A_{D, E}$ and $P G A_{C}$ is adopted, then a ratio of $P G A_{D, E} / P G A_{C}=$ 1.0 is strongly supported by the evidence from site-specific PSHA. For these reasons $P G A_{D, E}=P G A_{C}$ has been recommended in Module 1 of the geotechnical guidelines. It is important to emphasise that this equality applies only to the $P G A$, and not to the spectral shape, which is expected to strongly reflect the effects of site conditions and discriminate between Site Class C and Site Class D or E spectral characteristics.

Site Class C and Site Class D or E are the most prevalent site conditions for urban centres in NZ, and therefore, it seems appropriate the principal focus in setting the $P G A$ hazard to be on $P G A_{C}$ and $P G A_{D, E}$, and their respective ratios. By assuming $P G A_{A, B}=P G A_{C}=P G A_{D, E}, P G A$ at rock sites are also assumed to be equal to the $P G A$ of either Site Class C or $P G A_{V s 300}$ from site-specific PSHA. Given that Site Class A and B are considered together in NZS1170.5, and that the weaker of the two (Site Class B - rock, which includes a degraded or weathered rock) is defined with $V_{s, 30}>360 \mathrm{~m} / \mathrm{s}$ in the NZ site classification scheme (NZS1170.5), one may argue that the $P G A_{V s 300}$ from site-specific PSHA should be reasonably close to and a good approximation of $P G A V_{s}>360$ values, i.e., Site Class B. Hence, only values for $P G A C$ or $P G A V_{s} 300$ have been tabulated in Module 1, and

$P G A_{A, B}=P G A_{D, E}=P G A_{C}$

has been recommended in the geotechnical guidelines.

It is important to note that the authors do not want to downplay the important effects of site conditions on $P G A$ and especially on response spectra, including varying effects of soil nonlinearity on the site response. Such effects are recommended to be considered and appropriately incorporated in the upcoming seismic hazard update, including reconsideration of the classification scheme (criteria) for site classes. Until such robust evidence and interpretation is provided, however, the proposed site-class independent $P G A$ hazard is advantageous as it offers either similar or better accuracy than NZTA-BM and NZS1170.5 PGA hazards, and is certainly easier to implement.

\section{$P G A$ Hazard Maps for $R P=25$ and $500 \mathrm{yr}$}

The recommended PGA hazard for Module 1 of the geotechnical guidelines (Table in Appendix of [19]) is illustrated in Figures 13 and 14 where $P G A$ values for $R P=25$ $\mathrm{yr}$ and $R P=500 \mathrm{yr}$ are presented across NZ. The hazard for over 120 locations is shown including three groups of hazard information: locations for which NZTA-BM (Site Class C) hazard is used, the six sites and their associated regions (locations) for which the hazard has been defined in this study, as summarised in Table 1, and the hazard stipulated for the Canterbury Earthquake Region in the MBIE guidance [17,18]. Figures 13 a and 14 a show unweighted $P G A$ which is associated with a specific earthquake magnitude at each location (provided in Table in Appendix of [19]), whereas Figures 13b and 14b show respective magnitude-weighted $P G A 7.5$. Colour-code is used to define relevant ranges of $P G A \mathrm{~s}$ and visualise $P G A$ based zoning for the two return periods. 
The $P G A$ values for $R P=25 \mathrm{yr}$ show a relatively narrow range of values across NZ with all locations having $P G A<0.17 \mathrm{~g}$ and $P G A 7.5<0.15$ g. Focusing on Figure 13b which provides a better basis for zoning uniformity, three zones are defined with: (i) $P G A_{7.5}<0.05 \mathrm{~g}$; (ii) $0.05 \mathrm{~g} \leq P G A_{7.5}<0.10 \mathrm{~g}$; and, (iii) $0.10 \mathrm{~g} \leq P G A_{7.5}<0.15 \mathrm{~g}$. The highest $P G A$ s are observed for locations in the vicinity of major earthquake sources, whereas low $P G A_{7.5}<0.05 \mathrm{~g}$ are observed in two regions of NZ, at the north of North Island (Northland), and along the southeast coastline of the South Island.

Equivalent $P G A$ hazard plots for $R P=500 \mathrm{yr}$ are shown in Figure 14. The much wider range of $P G A$ s are split into four zones with: (i) $P G A_{7.5}<0.20 \mathrm{~g}$; (ii) $0.20 \mathrm{~g} \leq P G A_{7.5}<$ $0.30 \mathrm{~g}$; (iii) $0.30 \mathrm{~g} \leq P G A_{7.5}<0.50 \mathrm{~g}$; and, (iv) $P G A_{7.5} \geq$ $0.50 \mathrm{~g}$. The zones of relatively low, moderate and high $P G A \mathrm{~s}$ are somewhat different, but largely consistent with those depicted for $R P=25 \mathrm{yr}$. It is important to note that the relatively coarse increments of $\triangle P G A_{7.5}=0.10 \mathrm{~g}$ or $0.20 \mathrm{~g}$ used in the maps for $R P=500 \mathrm{yr}$ blur rather than emphasise differences in $P G A$ s between and within regions where rapid changes in $P G A$ occur over relatively short distances.

The $P G A$ hazard for $R P=25 \mathrm{yr}$ is more uniform, as it reflects the strong influence of the background seismicity model, which is more prominent in the contribution to the hazard for short return periods. Conversely, the $P G A$ hazard for $R P=500 \mathrm{yr}$ discriminates near-source regions close to major earthquake sources from locations at large distances from major faults. Thus, the highest $P G A$ s are obtained in near-source regions of earthquake sources with $M>7$ and relatively high-activity rates, especially along the Alpine Fault and the HSZ, which are characterised by $M>8$ earthquakes. By and large, Figures 13 and 14 show that the recommended interim $P G A$ hazard reasonably combines existing and new hazard information for the purpose of geotechnical assessment and design.
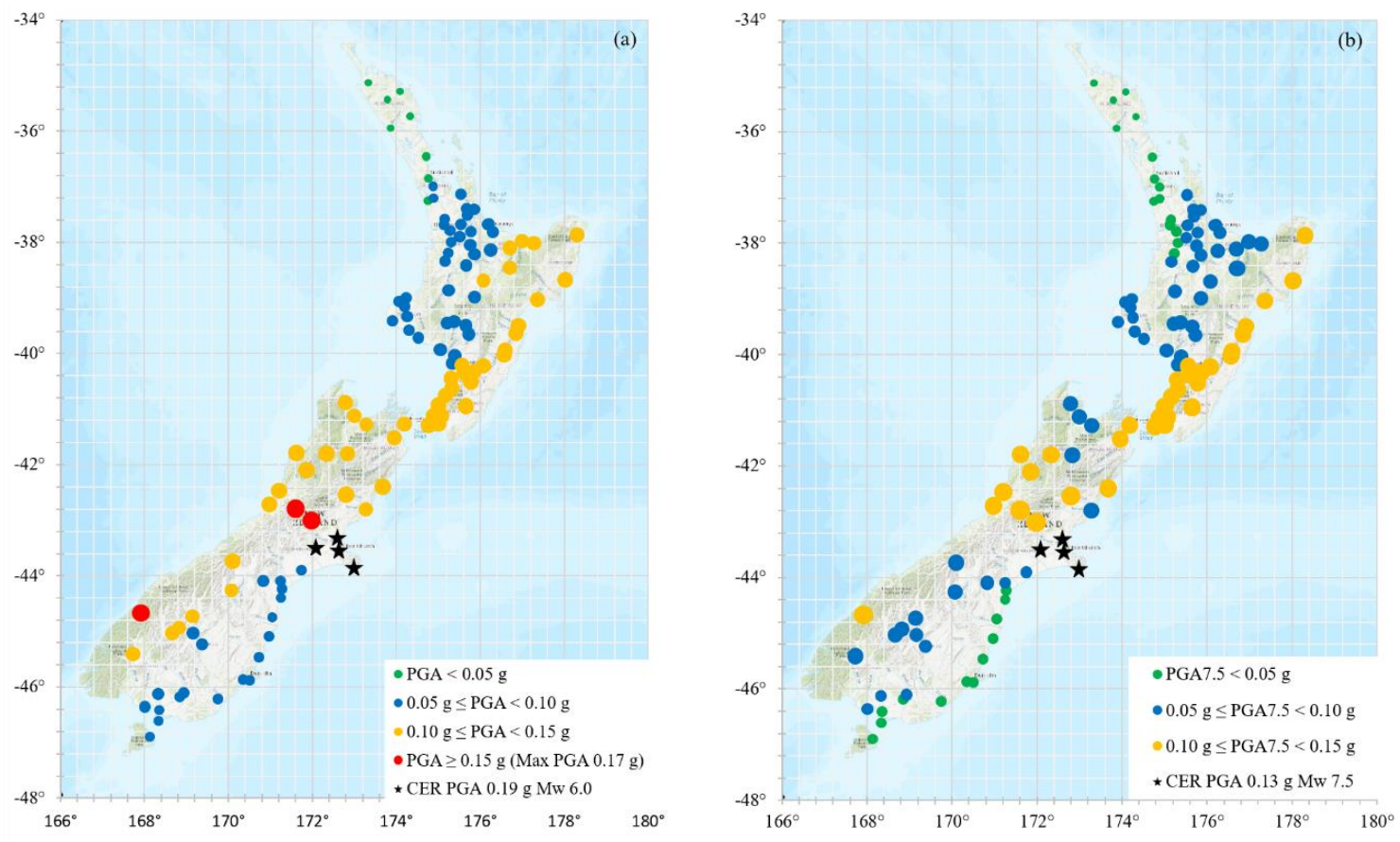

Figure 13: Recommended PGA Hazard for NZ for all site classes for RP=25 yr: (a) unweighted PGA; (b) PGA7.5.
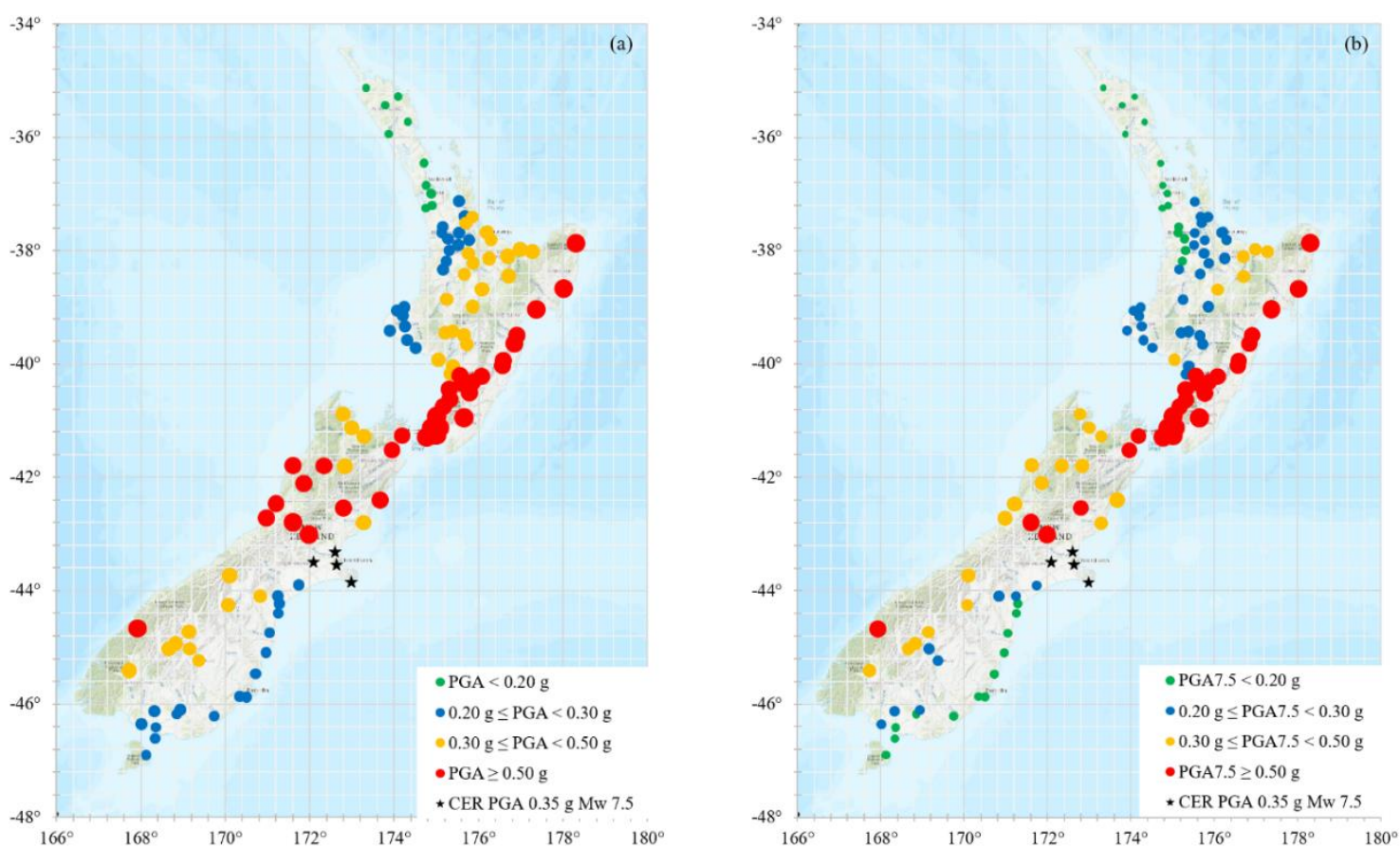

Figure 14: Recommended PGA Hazard for NZ for all site classes for RP=500 yr: (a) unweighted PGA; (b) PGA 7.5. 


\section{Evaluation of Spectral Accelerations}

As discussed in the introductory section of this paper, spectral accelerations are often needed to estimate the effects of structural response in geotechnical assessment and design. The $P G A$ hazard presented herein, and in Module 1 [19], cannot be used for this purpose, and scaling of the spectral shape factor from NZS1170.5 using the PGAs recommended herein is not appropriate. Instead, it is recommended either to use the elastic hazard spectra and procedures specified in NZS1170.5 for the appropriate site class, or to determine spectra using site-specific PSHA for the location of interest. Alternatively, the approach adopted in this study could be followed and site-specific PSHA could be performed for a selected set of representative locations to inform the development of interim hazard response spectra until results from the currently underway seismic hazard update of $\mathrm{NZ}$ are made available.

\section{CONCLUDING REMARKS}

Two codified hazards are currently available in NZ to estimate ground-motion parameters for geotechnical assessment and design. In the structural loading standard NZS1170.5 magnitude-weighted PGA7.5 hazard is essentially provided through the definition of hazard spectra, while NZTA Bridge Manual (NZTA-BM) provides $P G A$ hazard and associated earthquake magnitudes $\left(M_{\text {eff }}\right)$ specifically for geotechnical assessment and design. Detailed scrutiny of these two hazards has shown that they generally provide different $P G A$ values for locations across NZ. On average, $P G A 7.5$ (NZTA) is approximately $20 \%$ lower than the respective $P G A_{7.5(N Z S)}$, and in the extreme cases, $P G A_{7.5(N Z T A)}$ is $40 \%$ lower than $P G A 7.5(\mathrm{NZS})$.

Both NZS1170.5 and NZTA-BM PGA hazards have issues in the treatment of the earthquake magnitude. NZS1170.5 provides a magnitude-weighted $P G A_{7.5}$ hazard without any information about the $P G A$ and $M$ results directly obtained from PSHA before the application of magnitude-weighting. In addition, it employs a magnitude-scaling function which is not fully consistent with current liquefaction evaluation procedures (Figure 2). These two shortcomings effectively prevent rigorous evaluation of ground motions parameters for geotechnical design, from the NZS1170.5 hazard. The NZTA$\mathrm{BM}$ does provide the right format of the hazard for geotechnical design (i.e., $P G A$ and $M_{\text {eff }}$ for each location), however the definition of the effective magnitude is not provided. Importantly, results from site-specific PSHA show that for some NZ locations, $M_{\text {eff }}$ is substantially smaller than the mean earthquake magnitude $\bar{M}$ obtained from site-specific PSHA. These results suggest that the NZTA-BM PGA hazard is not appropriate for these locations.

Site-specific PSHA was performed at 24 carefully selected locations across NZ to scrutinise the above issues with NZS1170.5 and NZTA-BM hazards. The following are the key findings from the comparison of the hazards from site-specific PSHA and those presented in NZTA-BM and NZS1170.5:

1. For the majority of the investigated sites, i.e., for 15 out of 23 investigated locations (data for Christchurch not included), $P G A 7.5($ SS-PSHA) from site-specific PSHA is smaller than the respective PGA7.5(NZTA) from NZTA-BM. Hence, the NZTA-BM PGA hazard is conservative and overestimates the hazard for these locations, as compared to the site-specific $P G A$ hazard.

2. For six locations, the site-specific PGA7.5(SS-PSHA) is substantially higher than PGA7.5(NZTA), i.e., 35-45\% higher for Blenheim, Napier, Palmerston North and Whakatane, and $70-110 \%$ higher for Wellington and Gisborne.

3. The six locations, for which $P G A 7.5$ (SS-PSHA) $>>P G A 7.5$ (NZTA), are in the high seismicity zone characterised by $P G A>0.5$ $\mathrm{g}$ and $\bar{M}=7.1-7.8$. Importantly, for all six locations, there is a significant contribution (30-50\%) to the $P G A$ hazard from the Hikurangi Subduction Zone (HSZ), and the source-to-site distance specific to the HSZ is relatively short (mostly 20-40 km). The HSZ effect on the PGA hazard appears to be the key discriminating factor between the site-specific and NZTA-BM hazards, for these locations. This highlights the need for a careful evaluation of the seismic hazard for locations that are within $50 \mathrm{~km}$ from the HSZ, until more detailed guidance is provided through a comprehensive NZ-wide hazard update.

4. Comparisons of PGA7.5 hazards from site-specific PSHA and NZS1170 show a similar pattern as discussed above with reference to the NZTA-BM hazard. However, as $P G A 7.5$ (NZS) is consistently higher than $P G A 7.5$ (NZTA) (Figure 3), NZS1170.5 generally overestimates the site-specific $P G A 7.5$ hazard, and consequently also shows smaller underestimation of the $P G A$ hazard for locations affected by the HSZ. Yet, for two locations, Wellington and Gisborne, NZS1170.5 still substantially underestimates the $P G A 7.5$ (SS-PSHA) hazard from site-specific PSHA by $30 \%$ to $35 \%$.

An interim $P G A$ hazard has been recommended for use in geotechnical assessment and design, until the results of the national seismic hazard update are made available. It combines three sources of hazard information and guidance from NZTABM (for most of the NZ locations), site-specific PSHA from this study (for six locations and their associated regions), and the MBIE guidance for CER (Canterbury Earthquake Region). The recommended hazard (fully summarised in a table in the appendix of Module 1 in [19]) provides $P G A$ and earthquake magnitude $\left(M_{\text {eff }}\right.$ or $\left.\bar{M}\right)$ for $R P=25,50,100,250,500,1000$ and $2500 \mathrm{yr}$, for all locations across NZ. The $P G A$ hazard is applicable to all site classes without any modification and assumes $P G A_{A, B}=P G A_{C}=P G A_{D, E}$ based on results from sitespecific PSHA.

\section{ADDITIONAL CONSIDERATIONS FOR UPDATE OF NATIONAL SEISMIC HAZARD}

Given that a comprehensive study to update the seismic hazard of NZ has been recently initiated, the authors would like to highlight some additional observations from the study presented herein and general considerations in the development of national seismic hazard for design purposes.

\section{Seismic Hazard for Engineering Design}

Outputs from the seismic hazard (i.e., PSHA) are widely used in engineering design, urban and regional planning, and risk assessment. The issues discussed in this paper clearly illustrate that even within the realm of engineering design alone, different engineering problems and assessment methods require different ground-motion parameters from the seismic hazard, as they focus on different and complementary aspects in the evaluation of seismic performance. $P G A$ and $M$, which are important parameters in geotechnical assessment (in addition to spectral response characteristics), are not directly considered in current structural loading standard (NZS1170.5). Therefore, in the evaluation and interpretation of the seismic hazard, it is important to provide both appropriate forms of presentation and a range of relevant ground-motion parameters that satisfy various design needs.

The level of detail and granularity of hazard information should be carefully considered and adjusted while balancing the accuracy achievable in PSHA for any specific ground-motion parameter, and the accuracy needed in design. For example, presenting $P G A$ in increments of $0.01 \mathrm{~g}$ is neither a level of accuracy required for seismic design nor is reflecting the level of accuracy obtained for the PGA hazard from PSHA. Furthermore, it should be recognised that the national seismic 
hazard provides an opportunity for global hazard zoning, including the definition of principal hazard characteristics, dominant sources and associated uncertainties in their characterization, for each zone. Thus, the seismic hazard interpretation should aim at providing relevant information both at micro level (i.e., adequate granularity of information) and macro scale (e.g., global hazard zoning).

\section{Effects of GMMs, Site Classes and Unified Hazard Curve}

Results from the site-specific PSHA for 24 NZ locations [1] provide a basis to comparatively examine the effects of some of the uncertainties associated with $P G A$ hazard and the effects of hazard simplification or interpretation for design purposes. For example, four GMMs for active shallow crustal sources and two GMMs for subduction sources were used in the site-specific PSHA in [1] with a specific weighting scheme. These GMMs, when each is used as a single model (with $100 \%$ weight) for their relevant source type, yield eight different GMM combinations, for shallow crustal and subduction zone earthquakes. Hence, for each of the 24 locations, eight $P G A$ hazard curves were determined using the eight GMM combinations, and the differences between the respective eight hazard curves were used to estimate the effect of variation in GMM (or modelling uncertainty) on $P G A$. Bradley et al. [1] have shown that the variation in $P G A$, due to this variation in GMMs is approximately $20-30 \%$ in the site-specific PSHA.

Similarly, for each of the 24 locations, $P G A$ hazard curves were computed for $V_{s, 30}=200 \mathrm{~m} / \mathrm{s}$ and $300 \mathrm{~m} / \mathrm{s}$, which are representative of Site Class D and Site Class C conditions, respectively. Thus, the difference between $P G A$ hazard curves for $V_{s, 30}=200 \mathrm{~m} / \mathrm{s}$ and $300 \mathrm{~m} / \mathrm{s}$ provides an estimate for the effects of site class on $P G A$ specifically between Site Class C and Site Class D conditions. As depicted by the results from PSHA in Figure 12, the assumption for a site-class independent $P G A$ hazard, or $P G A_{D, E}=P G A_{C}$, introduces an approximate $20 \%$ error, which is similar with or slightly smaller than the uncertainty in the PGA hazard associated with GMM uncertainty.

Finally, results from site-specific PSHA were also used in [1] to quantify the error introduced in the $P G A$ hazard through the assumption for a uniform shape of the hazard curve adopted in NZS1170.5. The uniform hazard curve is effectively specified through the return period factor, $R$ (defined in Table 3.5, NZS1170.5; also discussed in Equation (1)). Bradley et al. [1] show that the error in the $P G A$ estimates for the 24 locations due to the assumed unique shape of the seismic hazard curve according to NZS1170.5 (i.e., same R factor values for all locations) could be as high as $40 \%$, which is greater than the variation in PGA due to GMM uncertainty or differences between site class $\mathrm{C}$ and $\mathrm{D}$ conditions previously discussed. These comparisons provide important context for the necessary considerations and trade-offs between simplifying assumptions and hazard interpretation when results from site-specific hazard are used to derive parametric expressions in seismic provisions.

Note that the effects of GMMs, site classes, and uniqueness of the hazard curve discussed above are specific to the $P G A$ hazard. Both absolute and relative magnitudes of these effects may change substantially if a different hazard parameter is considered in the assessment.

\section{ACKNOWLEDGMENTS}

The work on Revision 1 of Guidelines for Geotechnical Earthquake Engineering Practice was supported by the Ministry of Business, Innovation and Employment, NZ Geotechnical Society and Engineering NZ. The NZGS/Engineering NZ Panel for Revision 1 of the guidelines included the following members: Mike Stannard, Engineering NZ (project lead); Misko Cubrinovski, University of Canterbury (lead author of
Modules 1 and 3); Kevin McManus, McManus Geotech Ltd (lead author of Modules 1, 4 and 6); Rick Wentz, Wentz Pacific Ltd (lead author of Module 2); Nick Traylen, Geotech Consulting Ltd (lead author of Modules 2 and 6); Tony Fairclough, Tonkin \& Taylor (lead author of Module 2); Alexei Murashev, WSP (lead author of Module 5); Campbell Keepa, WSP (lead author of Module 5); Ananth Balachandra, Tonkin \& Taylor (NZGS representative); Kiran Saligame, MBIE; John Scott, Earthquake Commission (EQC). The authors would like to acknowledge the contributions of all panel members and institutions to this study and to the development of the guidelines series.

\section{REFERENCES}

1 Bradley BA, Cubrinovski M and Wentz F (2022). "Probabilistic seismic hazard analysis of peak ground acceleration for major regional New Zealand locations". Bulletin of the New Zealand Society for Earthquake Engineering, 55(1): 15-24. https://doi.org/10.5459/bnzsee.55.1.15-25

2 Makdisi FI and Seed HB (1978). "Simplified procedure for estimating dam and embankment earthquake-induced deformations". Journal of Geotechnical Engineering Division, 104(7): 849-867.

3 Bray JD and Rathje EM (1998). "Earthquake-induced displacements of solid-waste landfills". Journal of Geotechnical and Geoenvironmental Engineering, 124(3): 242-253. $\underline{\text { 0241(1998)124:3(242) }}$

4 Newmark NM (1965). "Effects of earthquakes on dams and embankments". Geotechnique, 15(2): 139-160.

https://doi.org/10.1680/geot.1965.15.2.139

5 Boulanger RW and Idriss IM (2014). "CPT and SPT Based Liquefaction Triggering Procedures". Report No. UCD/CGM-14/01. Davis: Center for Geotechnical Modeling, Department of Civil and Environmental Engineering, University of California, Davis.

6 NZGS (2010). "Geotechnical Earthquake Engineering Practice: Module 1 - Guideline for the Identification, Assessment and Mitigation of Liquefaction Hazards". New Zealand Geotechnical Society (NZGS), 28pp.

7 Cubrinovski M, Green RA, Allen J, Ashford S, Bowman E, Bradley B, Cox B, Hutchinson T, Kavazanjian E, Orense R, Pender M, Quigley M and Wotherspoon L (2010). "Geotechnical reconnaissance of the 2010 Darfield (Canterbury) earthquake". Bulletin of the New Zealand Society for Earthquake Engineering, 43(4): 243-320. https://doi.org/10.5459/bnzsee.43.4.243-320

8 Cubrinovski M, Bradley B, Wotherspoon L, Green R, Bray J, Wood C, Pender M, Allen J, Bradshaw A, Rix G, Taylor M, Robinson K, Henderson D, Giorgini S, Ma K, Winkley A, Zupan J, O’Rourke T, De Pascale G and Wells D (2011). "Geotechnical aspects of the 22 February 2011 Christchurch earthquake". Bulletin of the New Zealand Society for Earthquake Engineering, 44(4): 205-226. https://doi.org/10.5459/bnzsee.44.4.205-226

9 MBIE and NZGS (2016). "Geotechnical Earthquake Engineering Practice: Module 1 - Overview of the Guidelines". Ministry of Business, Innovation and Employment (MBIE) and New Zealand Geotechnical Society (NZGS), Wellington, NZ, 28pp.

10 SNZ (2004). "NZS1170.5: Structural Design Actions. Part 5: Earthquake Actions-New Zealand". Standards New Zealand (SNZ), Wellington, NZ, 79pp.

11 NZTA (2014). “Bridge Manual”. NZTA Bridge Manual $3^{\text {rd }}$ Edition, New Zealand Transport Agency (NZTA), NZ. 
12 NZTA (2018). "Bridge Manual". NZTA Bridge Manual $3^{\text {rd }}$ Edition, Amendment 3, October 2018, New Zealand Transport Agency (NZTA), NZ.

13 NZTA (2018). "Bridge Manual Commentary". NZTA Bridge Manual $1^{\text {st }}$ Edition, Amendment 0, October 2018, New Zealand Transport Agency (NZTA), NZ.

14 McVerry GH (2003). "From hazard maps to code spectra for New Zealand". Proceedings 2003 Pacific Conference on Earthquake Engineering, 13-15 February, Christchurch, NZ, Paper No. 34.

15 Idriss IM (1985). "Evaluating seismic risk in engineering practice". Proceedings of the $11^{\text {th }}$ International Conference of Soil Mechanics and Foundation Engineering, 12-16 August, San Francisco, USA, 1: 255-320.

16 Stirling M, McVerry G, Gerstenberger M, Litchfield N, Van Dissen R, Berryman K, Barnes P, Wallace L, Villamor P, Langridge R, Lamarche $G$, Nodder S, Reyners M, Bradley B, Rhoades D, Smith W, Nicol A, Pettinga J, Clark $\mathrm{K}$ and Jacobs K (2012). "National seismic hazard model for New Zealand: 2010 Update". Bulletin of the Seismological Society of America, 102(4): 1514-1542. https://doi.org/10.1785/0120110170
17 MBIE (2012). "Repairing and Rebuilding Houses Affected by the Canterbury Earthquakes". Version 3, December 2012, Ministry of Business, Innovation and Employment (MBIE), NZ.

18 MBIE (2014). "Clarifications and Updates to the Guidance 'Repairing and Rebuilding Houses Affected by the Canterbury Earthquakes". Issue 7, Ministry of Business, Innovation and Employment (MBIE), NZ.

19 MBIE and NZGS (2020). "Geotechnical Earthquake Engineering Practice: Module 1 - Overview of the Guidelines and Seismic Hazard for Geotechnical Assessment". Ministry of Business, Innovation and Employment (MBIE) and New Zealand Geotechnical Society (NZGS), (in Preparation).

20 Cubrinovski M, Rhodes A, Ntritsos $\mathrm{N}$ and van Ballegooy S (2019). "System response of liquefiable deposits". Soil Dynamics and Earthquake Engineering, 124: 212-229. https://doi.org/10.1016/j.soildyn.2018.05.013 
APPENDIX: MAGNITUDE-SCALING FACTORS IN LIQUEFACTION ASSESSMENT

As the magnitude scaling (weighting) is a central feature in both geotechnical assessment and current seismic provisions for structural loading (NZS1170.5), key characteristics behind the concept and particular magnitude scaling functions are briefly discussed below.

The concept of magnitude scaling in liquefaction assessment is associated with one fundamental characteristic of the liquefaction resistance of soils, which is observed in laboratory tests. Namely, in liquefaction tests performed in the laboratory, a relationship is established between the uniform amplitude of the applied shear stress (load) on the soil, and the number of loading cycles required to liquefy the soil or cause 5\% doubleamplitude (peak-to-peak) strain under that loading amplitude. This relationship is also known as the liquefaction resistance curve (LRC).

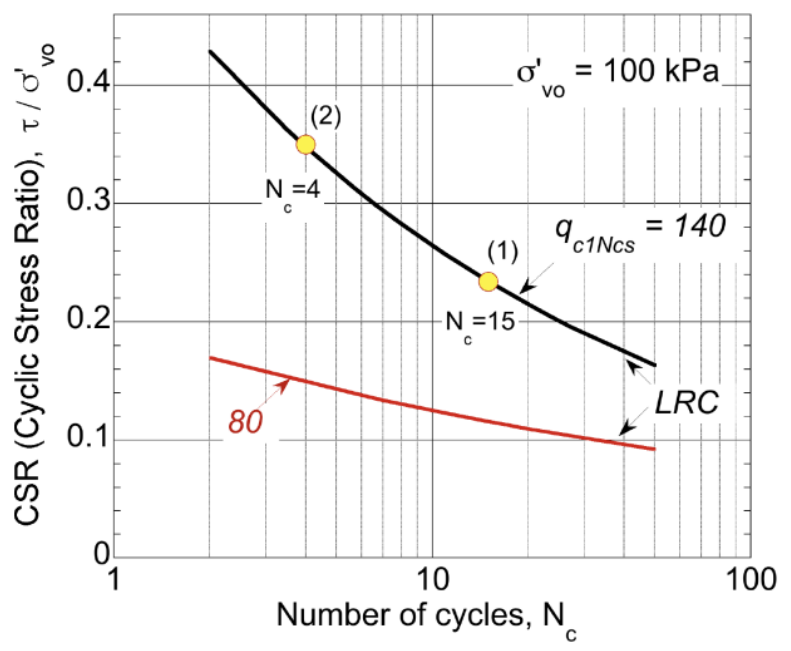

Figure A1: Liquefaction resistance curves for relatively loose sand $\left(q_{c 1 N c s}=80\right)$ and medium dense sand $\left(q_{c 1 N c s}=140\right)$ derived from the liquefaction triggering procedure of Boulanger and Idriss [5], as illustrated in Cubrinovski et al. [20].

Examples of LRCs for a relatively loose soil $\left(q_{c I N c s}=80\right)$ and medium dense soil $\left(q_{c I N c s}=140\right)$ are shown in Figure A1. Here, $C S R$ is the measure for the applied amplitude of shear stress (load), $N_{c}$ is the number of uniform-amplitude cycles, and $q_{c l N c s}$ (normalised clean sand equivalent cone tip resistance) is a field measure for the density of the soil. All $C S R-N_{c}$ combinations on a given LRC indicate identical soil response (i.e., $5 \%$ peak-topeak strain), and therefore, the LRC actually specifies an equal damage potential for a given soil density. For example, as indicated with the two symbols for $q_{c l N c s}=140,4$ cycles of uniform amplitude $C S R=0.35$ are equivalent to 15 cycles of $C S R=0.23$, as both load combinations would cause 5\% peakto-peak strain in the soil, at 4 and 15 cycles, respectively. As depicted in Figure A1, the position and shape of the LRC depend on the density of the soil.

The magnitude-scaling functions shown in Figure 2 for $q_{c I N c s}=$ 80 and 140 were obtained directly from the two LRCs shown in Figure A1. In the conversion process, the magnitude-scaling factor is defined as $M S F=C S R_{N_{c}} / C S R_{N_{c}=15}$, for a given LRC, and a $N_{c}=f(M)$ empirical correlation is used to express $M S F$ as a function of the earthquake magnitude $(M)$ instead of number of cycles $\left(N_{c}\right)$. The normalization with $C S R_{N_{c}=15}$, yields $M S F=$ 1.0 at $M=7.5$, as the reference earthquake magnitude $M=7.5$ is associated with $N_{c}=15$ cycles. Thus, in Figure 2, all curves have $M S F=1.0$ at $M=7.5$, and the shape of the $M S F$ function corresponds to the shape of the respective LRC, as illustrated in Figures 2 and $\mathrm{A} 1$ for the $q_{c l N c s}=80$ and 140 curves.

The two symbols corresponding to $\left(C S R=0.35 ; N_{c}=4\right)$ and $\left(C S R=0.23 ; N_{c}=15\right)$ in Figure A1 (for $\left.q_{c l N c s}=140\right)$, are also shown in Figure 2. They essentially imply in Figure 2 that if an earthquake with a magnitude $M=7.5$ and $P G A_{7.5}$ causes liquefaction in soil with $q_{c I N c s}=140$, then an earthquake with a magnitude $M=5.5$ would require 1.49 times higher $P G A$ or $P G A_{55}=M S F \cdot P G A_{75}=1.49 \cdot P G A_{75}$ to liquefy the soil (as $M=$ 5.5 will have only 4 cycles as compared to 15 cycles for $M=$ 7.5).

In this manner, the magnitude-scaling concept provides a relatively easy and practical way to estimate the liquefaction resistance of soils for earthquakes with different magnitudes (i.e., different significant duration or, equivalently, different number of significant-amplitude cycles). The solid lines in Figure 2 show magnitude-scaling relationships for four soil densities $\left(q_{c I N c s}\right.$ values) defined according to the simplified liquefaction triggering procedure of Boulanger and Idriss [5], which is the recommended method in the guidelines for earthquake geotechnical engineering practice in NZ. Note that, apart from the $M S F$ for $q_{c I N c s}=140$, Boulanger and Idriss [5] employ different MSFs from that embodied in the NZS1170.5 hazard. 